\title{
Understanding seasonal weight loss tolerance in dairy goats: a transcriptomics approach
}

José Ricardo Parreira ${ }^{1,2}$, Lorenzo Enrique Hernández-Castellano ${ }^{3}$, Anastasio Argüello ${ }^{4}$, Juan Capote ${ }^{5}$, Noemí Castro ${ }^{4}$, Susana de Sousa Araújo ${ }^{2+}$ and André Martinho de Almeida ${ }^{6^{*}+}$

\begin{abstract}
Background: Seasonal weight loss (SWL) is a very important limitation to the production of ruminants in the Mediterranean and Tropical regions. In these areas, long dry seasons lead to poor pastures with low nutritional value. During the dry season, ruminants, particularly those raised in extensive production systems, lose around 30\% of their body weight. Seasonal weight loss has important consequences on animal productive performance and health. In this study, RNA sequencing was used to characterize feed restriction effects in dairy goat of 2 breeds with different SWL tolerance: Majorera (tolerant) and Palmera (susceptible). Nine Majorera and ten Palmera goats were randomly distributed in a control and a restricted group: Majorera Control (adequately fed; $M C ; n=4$ ), Palmera Control (adequately fed; PC; $n=6$ ), Majorera Restricted (feed restricted; ME; $n=5$ ) and Palmera Restricted (feed restricted; $P E ; n=4$ ). On day 22 of the trial, mammary gland biopsies were collected for transcriptomics analysis.

Results: From these samples, 24,260 unique transcripts were identified. From those, 82 transcripts were differentially expressed between MC and ME, 99 between PC and PE, twelve between both control groups and twenty-nine between both restricted groups.

Conclusions: Feed restriction affected several biochemical pathways in both breeds such as: carbohydrate and lipid transport; intracellular trafficking, RNA processing and signal transduction. This research also highlights the importance or involvement of the genes in tolerance (ENPP1, S-LZ, MT2A and GPNB) and susceptibility (GPD1, CTPS1, ELOVL6 and NR4A1) to SWL with respectively higher expression in the Majorera restriced group and the Palmera restricted group in comparison to the control groups. In addition, results from the study may be extrapolated to other dairy ruminant species.
\end{abstract}

Keywords: Goat, Mammary gland, Transcriptomics, RNA-sequencing, Seasonal weight loss

\footnotetext{
* Correspondence: aalmeida@isa.ulisboa.pt

†'Susana de Sousa Araújo and André Martinho de Almeida contributed equally to this work.

${ }^{6}$ LEAF - Linking Landscape, Environment, Agriculture And Food, Instituto

Superior de Agronomia, Universidade de Lisboa, Tapada da Ajuda, 13409-017 Lisbon, Portugal

Full list of author information is available at the end of the article
}

(c) The Author(s). 2020 Open Access This article is licensed under a Creative Commons Attribution 4.0 International License, which permits use, sharing, adaptation, distribution and reproduction in any medium or format, as long as you give appropriate credit to the original author(s) and the source, provide a link to the Creative Commons licence, and indicate if changes were made. The images or other third party material in this article are included in the article's Creative Commons licence, unless indicated otherwise in a credit line to the material. If material is not included in the article's Creative Commons licence and your intended use is not permitted by statutory regulation or exceeds the permitted use, you will need to obtain permission directly from the copyright holder. To view a copy of this licence, visit http://creativecommons.org/licenses/by/4.0/ The Creative Commons Public Domain Dedication waiver (http://creativecommons.org/publicdomain/zero/1.0/) applies to the data made available in this article, unless otherwise stated in a credit line to the data. 


\section{Background}

Ruminant production plays an important role in the economy and livelihood of countries all across the world. Cattle and small ruminant production are particularly important in developing countries. Small ruminants, mainly sheep (Ovis aries) and goats (Capra hircus), are adapted to extensive production systems, particularly in drought-prone areas of the world. Such regions are characterized by the existence of dry seasons that affect growth, quality and availability of pastures, which directly impacts animal performance. Consequently, animals raised under extensive conditions are frequently subjected to feed restriction, a problem known as Seasonal Weight Loss or SWL [1].

Seasonal Weight Loss is considered one of the most significant problems for animal production worldwide. In fact, in regions such as the tropics or the Mediterranean basin, animals may lose up to $30 \%$ of their body weight (BW). Seasonal Weight Loss has been described in various regions of the globe such as West Africa [2, 3], South Africa [4, 5], Western Australia [6, 7] and the Canary Islands $[8,9]$. The use of supplementation (either fodder, grain or concentrate feeds) is a possible solution to overcome SWL. Nevertheless, it is very costly and challenging, particularly in extensive production systems. Alternatively, the use of local breeds, known to be tolerant to SWL, is a very interesting and sustainable possibility for those regions as it is much less expensive and easy to implement in comparison to supplementation [1].

The Canary Islands (Spain) is a subtropical archipelago, with different climates across the islands. The western islands, namely La Palma, have a humid temperate climate. On the contrary, the easternmost islands, particularly Fuerteventura and Lanzarote have a dry climate [10]. These two different parts of the archipelago have in turn different rainfall that lead to differences in pasture availability and therefore in animal production systems. As a result of specific animal adaptations to the divergent climates of the islands, three local goat breeds are found. Goats from the Canary Islands descend from ancestors brought in from North Africa and Spain in the fifteenth and sisteenth centuries [11]. These breeds are the Majorera (from Gran Canaria and Fuerteventura), the Palmera from the island of La Palma and finally the Tinerfeña (from Tenerife island) [11]. Majorera goats have considerably high milk yields $(500-550 \mathrm{~kg}$ of milk per lactation), being well adapted to dry regions with limited water and pasture availability and are therefore tolerant to SWL $[8,9]$. On the contrary, Palmera goats are adapted to regions with higher rainfall, with better pastures, being susceptible to SWL [12]. We have demonstrated such different adaptation levels in previous work on productive and clinical biochemistry physiological parameters $[8,9]$.
The advent of Next Generation Sequencing (NGS) led to important developments in the field of animal science through the application of these techniques with different examples in reproduction and physiology found in the literature $[13,14]$. In fact, and similarly to proteomics [15], numerous applications may be found in the literature, for mammary gland physiology, growth and involution, productive function, etc. [16].

Previous studies from our group have studied growth and productive traits [8] as well as different blood metabolites and hormone profiles [9] in Majorera (SWL tolerant) and Palmera (SWL susceptible) goat breeds subjected to feed restriction in order to simulate SWL. In such studies, significant differences between breeds were observed for blood metabolites (creatinine, urea, non-esterified fatty acids, cholesterol, IGF-1 and T3) as a consequence of underfeeding, highlighting major differences between breeds. We have recently extended that study to the effects of feed restriction on the mammary gland secretory tissue proteome [17, 18], metabolome [19] and fatty acid [20] profiling. We highlighted that the Majorera breed had a persistent accretion of proteins related to the immune system by comparison to Palmera goats [17]. Additionally, weight loss led in the Palmera breed to an accumulation of proteins related to apoptosis, overall confirming that the two goat breeds have different physiological reactions to SWL [17]. In this research, we hypothesize that differences observed between breeds and their response to feed restriction are reflected at the transcriptomic level. We therefore characterized the effects of feed restriction on the mammary gland secretory tissue transcriptome using an RNA sequencing (RNA-Seq) approach. The results highlighted major genes and biochemical pathways affected by weight loss in the two breeds.

\section{Results}

Goat body weights and productive performance

Fluctuations in body weight (BW) and milk yield in both breeds (Majorera and Palmera) under both conditions (feed restriction and control) were previously described and discussed [8]. Briefly, both control groups showed similar milk yields and slight weight fluctuations throughout the trial. Animals from the feed restricted groups showed decreased milk yields (86.9 and 87.2\% reduction in the Majorera and Palmera breeds, respectively) and decreased $13 \%$ of their initial body weight at the end of the trial.

\section{Global overview of gene expression}

Twelve RNA-seq libraries representing biological triplicates of studied experimental conditions were constructed 
and sequenced to capture transcriptome changes associated with the different breeds and feed regimes.

The sequencing of the $12 \mathrm{cDNA}$ libraries resulted in a total of $700,489,334$ raw reads, with an average of 58 , $374,111.17$ raw reads/sample. Information about the library characterization for all samples can be found in Table 1.

Of the 24,260 genes found as output of the RSEM analysis, 9731 genes were found expressed amongst all samples (raw number counts $>100$ in at least one sample) (Supplementary Material 1). Casein beta (CSN2), casein kappa (CSN3), progestagen-associated endometrial protein $(P A E P)$ and $\alpha 2$-casein (CSN1S2) were among the identified sequences with highest total raw read counts, suggesting no ribosomal RNA (rRNA) contamination during library preparation. In addition, 82 transcripts showed significant changes in gene expression abundance $\left(\log _{2} \mathrm{FC}<-1.5\right.$ or $\log _{2} \mathrm{FC}>1.5-, P<0.05$ and FDR $<0.05$ ) between MC (Majorera control) and ME (Majorera restricted), 99 between PC (Palmera control) and PE (Palmera restricted), 12 between both control groups and 29 between both restricted groups (Fig. 1). Some of the identified genes were differentially expressed across the different comparisons. These results are detailed in Supplementary materials 2, 3, 4, and 5.

Cluster of Gene Ontology (COG)-based categorization describes the major functional classification regarding genes whose expression was trigggered in response to feed restriction in both breeds. An analysis of the differentially expressed genes (DEGs) in the four experimental groups (MC, PC, ME and PE) using the COG database is shown in Fig. 2. More details are available in Supplementary Material 7. For the two Majorera groups, sixteen COG terms were retrieved. These included for instance transcription, intracellular trafficking, carbohydrate transport and metabolism or signal transduction among other functions. For the Palmera groups comparison, eighteen COG terms were found including posttranslational modification and protein turnover, aminoacid transport and metabolism or defense mechanism functions. The comparison of the two control groups involved seven COG terms (e.g. RNA processing and modification or signal transduction mechanisms functions). Finally, the comparison of the two restricted groups led to eleven COG terms that included for instance nucleotide transport and metabolism, translation or energy production and conversion functions.

Hierarchical clustering made using the $\log _{2}$ FPKM (fragments per kilo base per million mapped reads) values illustrate that all animals belonging to the same experimental condition are clustered together (Figs. 3 and 4). These show groups of genes that have differential expression in one of the pairwise comparisons. Examples include for instance, genes POSTN and RNASE1 (over expression in $\mathrm{MC}$ when compared to $\mathrm{PC}$, see in Fig. 4a) or TP53INP2 and RFX4, down-regulated in the ME group when compared to PC (Fig. 3). A Principal Component Analysis partially supports the previously mentioned results, evidencing also a considerable level of variability between samples (Fig. 5). Nevertheless it also evidences that the majority of the differences observed between both breeds results from the feed restriction treatment applied.

\section{Gene expression differences between groups}

Please refer to Supplementary material 2, 3, 4, and 5 for a comprehensive description of the expression differences between comparisons. Overall, the Palmera breed

Table 1 Individual characterization of the constructed RNA-seq libraries

\begin{tabular}{|c|c|c|c|c|c|c|c|}
\hline Sample & Number of total bases & Number of raw reads & GC (\%) & Q20 (\%) & Q30 (\%) & Number of mapped reads & Mapped reads (\%) \\
\hline $\mathrm{MC1}$ & $5,513,718,472$ & $54,591,272$ & 48.78 & 95.44 & 91.40 & $38,107,784$ & 70 \\
\hline MC2 & $6,080,971,034$ & $60,207,634$ & 50.15 & 93.42 & 88.97 & $37,251,096$ & 62 \\
\hline MC3 & $5,746,342,278$ & $56,894,478$ & 49.59 & 94.41 & 90.06 & $36,979,098$ & 65 \\
\hline PC1 & $5,016,985,322$ & $49,673,122$ & 50.11 & 93.90 & 89.47 & $29,401,920$ & 59 \\
\hline PC2 & $5,328,847,668$ & $52,760,868$ & 49.3 & 94.97 & 90.84 & $35,422,448$ & 67 \\
\hline PC3 & $5,462,951,832$ & $54,088,632$ & 49.72 & 94.48 & 90.17 & $30,622,836$ & 57 \\
\hline ME1 & $5,440,414,692$ & $53,865,492$ & 48,46 & 94.74 & 90.68 & $36,580,712$ & 68 \\
\hline ME2 & $6,052,955,250$ & $59,930,250$ & 47.71 & 94.75 & 90.84 & $41,953,734$ & 70 \\
\hline ME3 & $5,943,007,458$ & $58,841,658$ & 48.44 & 95.30 & 91.30 & $40,345,942$ & 69 \\
\hline PE1 & $7,931,399,306$ & $78,528,706$ & 49.27 & 95.06 & 91.03 & $54,606,756$ & 70 \\
\hline PE2 & $6,455,995,144$ & $63,920,744$ & 48.33 & 94.62 & 90.57 & $45,854,954$ & 72 \\
\hline PE3 & $5,775,834,278$ & $57,186,478$ & 48.66 & 95.13 & 91.06 & $38,565,456$ & 67 \\
\hline
\end{tabular}

MC Majorera Control, PC Palmera Control, ME Majorera Restricted, PE Palmera Restricted. Total bases, raw and mapped reads, GC content (\%), Q20 (\%) and Q30 (\%) of each sequenced sample on the Illumina Hiseq 2500 (Illumina, San Diego, CA, USA) are described. Percentage of mapped reads was calculated using the number of mapped reads/raw reads 


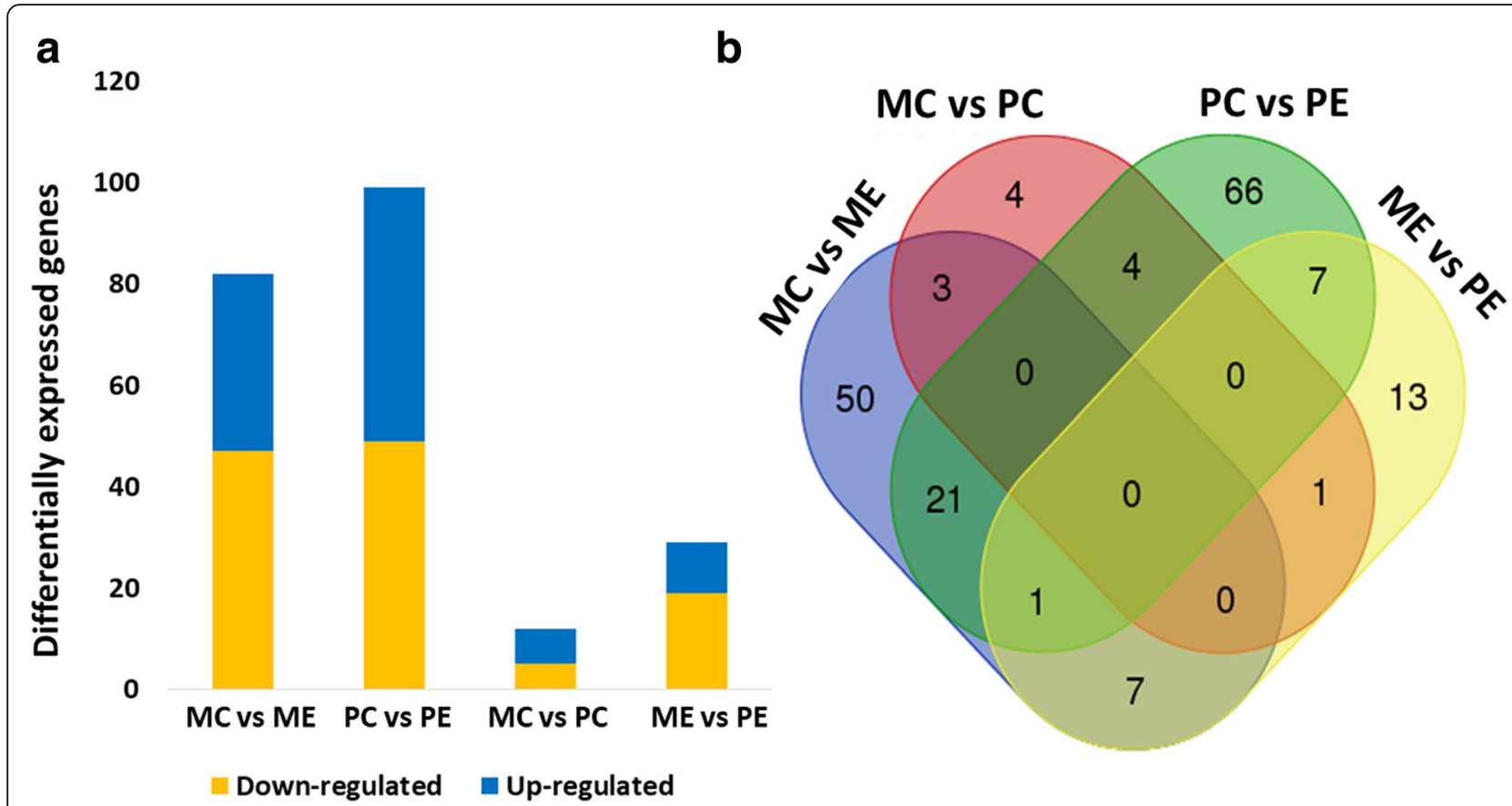

Fig. 1 Differential gene expression results. a - The number of differentially (up and down-regulated) expressed genes (DEGs) in each comparison established for the study. $\mathbf{b}$ - Venn diagram analysis of DEGs in each comparison established for the study. The overlapping regions show common genes among the main comparisons established. MC - Majorera Control ME - Majorera Restricted; PC - Palmera Control and PE Palmera Restricted. Parameters used: $P$-value and FDR $<0.05$, Log2FC $>1.5$ or $<-1.5$, and raw number counts $>100$ in at least one sample

Q: Secondary metabolites biosynthesis, transport and catabolism

J: Translation, ribosomal structure and biogenesis

$\mathrm{H}$ : Coenzyme transport and metabolism

F: Nucleotide transport and metabolism M: Cell wall/membrane/envelope biogenesis

Z: Cytoskeleton

C: Energy production and conversion

W: Extracellular structures

V: Defense mechanisms

I: Lipid transport and metabolism

E: Amino acid transport and metabolism

A: RNA processing and modification

$P$ : Inorganic ion transport and metabolism

K: Transcription

G: Carbohydrate transport and metabolism

U: Intracellular trafficking, secretion, and vesicular transport

$\mathrm{T}$ : Signal transduction mechanisms

O: Posttranslational modification, protein turnover, chaperones

S: Function unknown

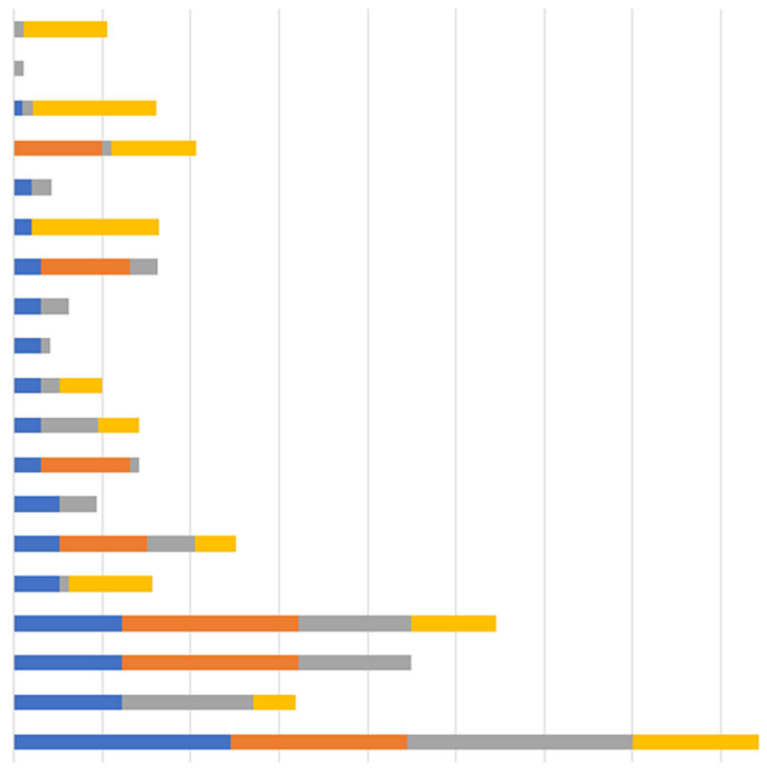

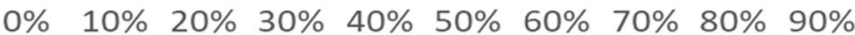

\section{$\mathrm{MC}$ vs ME $\square \mathrm{MC}$ vs PC $\square \mathrm{PC}$ vs PE $\square \mathrm{ME}$ vs PE}

Fig. 2 Graphic representation of the percentage of genes within each orthologous group obtained via Blast2GO, Cluster of orthologs e-Value 1e3 for the four studied comparisons. MC - Majorera Control, PC - Palmera Control; ME - Majorera Restricted and PE - Palmera Restricted. For all comparisons: $p$-value and $\mathrm{FDR}<0.05, \log 2 \mathrm{FC}>1.5$ or $<-1.5$, and raw number counts $>100$ in at least one sample 
a
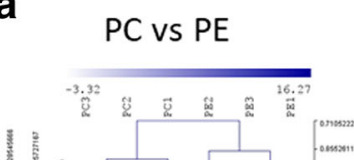

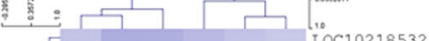

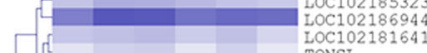

THI TOC1021

MYCL

EAM135B

LOC100861296

SPTLC3

WNT5A

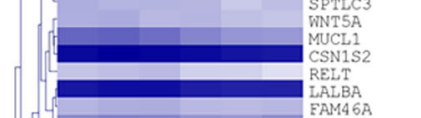

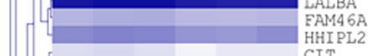
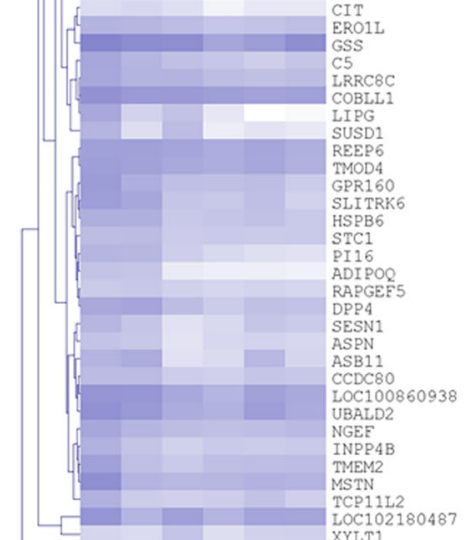

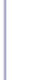
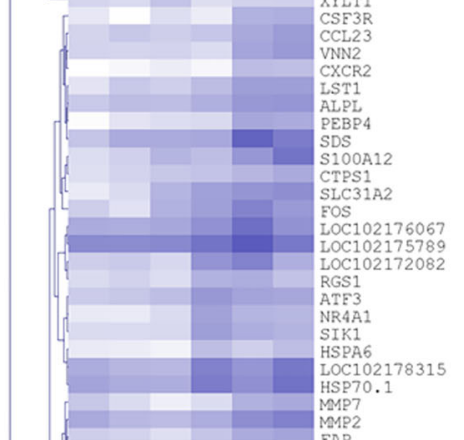

(1)
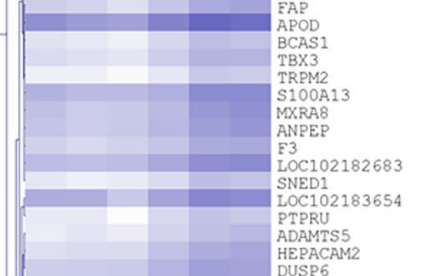

DUPP6

GPR110

LOC102188913

RARRES1

LOC102173668

LOC10218

DUSP1

ZFP36

\section{b}

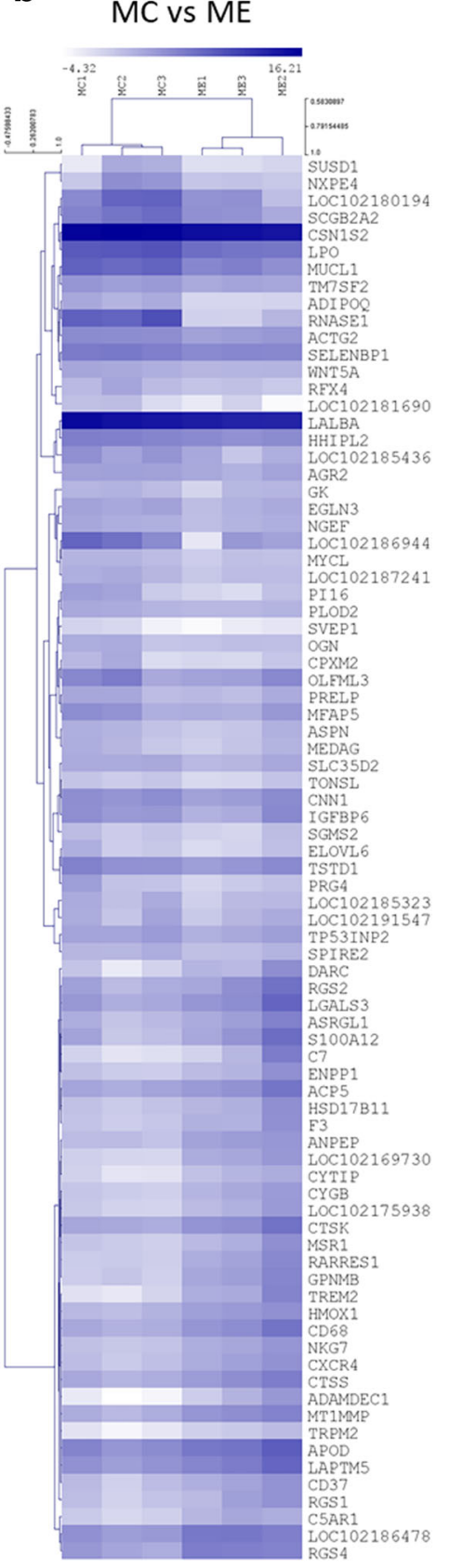

Fig. 3 Heatmaps and hierarchical clustering of the differentially expressed genes in the Palmera (a panel) and the Majorera (b panel) animals. MC - Majorera Control; PC - Palmera Control; ME - Majorera Restricted and PE - Palmera Restricted. Gene symbols are displayed in rows. Dark blue indicates high expression whereas light blue indicates low expression 

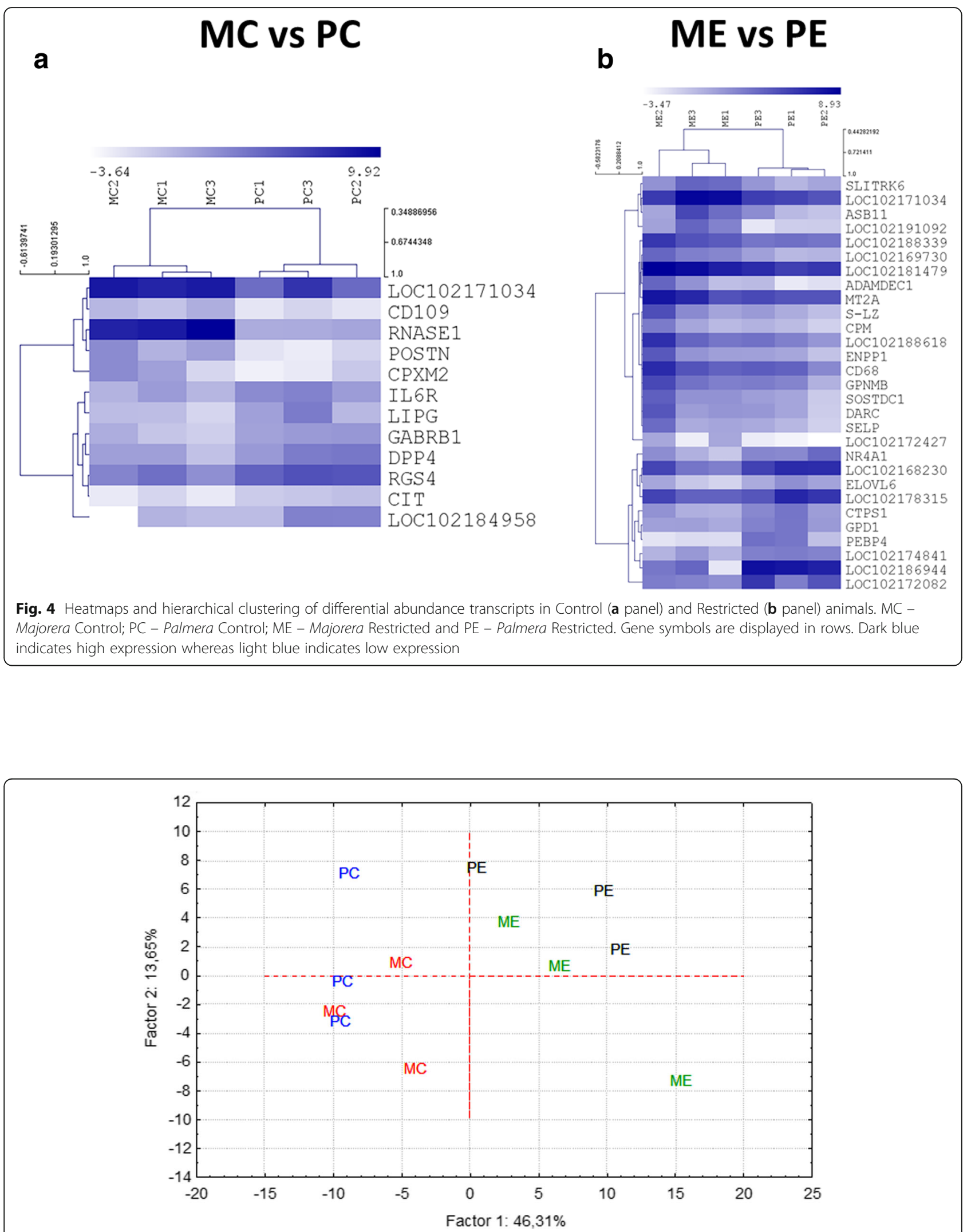

Fig. 5 Principal Component Analysis (PCA) scatterplot of the four experimental groups using all differentially expressed genes. Values of FPKM were $\log _{2}$ transformed before computation. MC - Majorera Control; PC - Palmera Control; ME - Majorera Restricted and PE - Palmera Restricted 
showed the highest number of DEGs compared to the Majorera breed (see also Fig. 3).

A comparison between both control groups (MC vs. PC) showed only twelve differentially expressed $(P<0.05)$ genes (Supplementary material 2). Five up-regulated genes were found in the MC group (RNASE1, POSTN, CPXM2, LOC102171034 and CD109). A total of seven upregulated genes were found in the PC group (CIT, IL6R, GABRB1, DPP4, RGS4, LIPG and LOC102184958).

The Majorera mammary gland transcriptome was affected by feed restricition as shown in Supplementary material 3. The genes found to have differential expression were involved in a plethora of biological functions: from RNA processing to energy production, from amino acid transport and nucleotide transport to transcription or signal transduction; and defense mechanisms. Additionally, twenty-four DEGs have been categorized with an unknown function. The DEGs involved in RNA processing (e.g RNASE1 and IGFBP6), signal transduction (e.g. NGEF, PI16 and SVEP1) and transcription (e.g. TP53INP2 and RFX4) were mainly down-regulated in the ME group. In this comparison, the majority of the intracellular trafficking, secretion, and vesicular transport pathways were up-regulated in the ME group. The list includes for instance DEGs such as CXCR4, MSR1, NKG7 or CD68. The extracellular structures had one down-regulated DEG (OLFML3) and two up-regulated DEGs (MT1MMP and LGALS3) in the ME group. Two DEGs associated to cytoskeleton were up-regulated in the MC group compared to the ME group (ACTG2 and CNN1).

Similar to the Majorera breed, and as shown in Supplementary material 4 , the Palmera mammary gland transcriptome was also affected by feed restriction. A total of 99 genes had significantly $(P<0.05)$ differential expression, about $20 \%$ more than in the Majorera breed. This suggests that the Palmera breed is more affected by feed restriction. The list of DEGs include COG terms such as RNA processing, amino acids transport and carbohydrates transport. It also includes translation, transcription, protein turnover, and signal transduction, among others. As in the Majorera breed, twenty-four DEGs were detected with unknown roles. The majority of genes involved in lipid, carbohydrate, amino acid and nucleotide transport are up-regulated in the control group.

Finally, the comparison between the two restricted groups (see Supplementary material 5) led to twenty-nine DEGs. These included for instance ASB11, ADAMDEC1 or $S-L Z$ (higher expression in the ME group) and GPD1, CTPS1 and ELOVL6 (higher expression in the PE group).

\section{Reverse Transcribed Quantitative PCR validation}

The RNA-Seq results were validated using Reverse Transcribed Quantitative PCR. A comparison of the expression levels quantified using RNA-Seq and RTqPCR is depicted for six randomly chosen genes (DPP4; ELOVL6; GK; LIPG; RNASE1 and LOC102182683) (Fig. 6). Results are fully detailed in Supplementary material 8.

A correlation was calculated between the $\log _{2}$ fold change values calculated using the two approaches (qPCR and RNA-Seq) as presented in Fig. 7. A significant positive correlation $\left(R^{2}=0.9587\right)$ was obtained for the mentioned genes. Such correlation supports the accuracy and validation of the RNA-Seq analysis.

\section{Discussion}

In this study, we used a global transcriptomic approach (RNA-Seq) to investigate the molecular mechanisms triggered in the mammary gland as a consequence of weight loss caused by feed restriction in two dairy goat breeds differently adapted to SWL: the tolerant Majorera and the susceptible Palmera. These breeds have natural differences in size and furthermore have evolved in very different ecosystems which led to differences in their adaptation to nutritional stress [8]. Differences between breeds are mainly based on how specific metabolic pathways were affected by feed restriction, although there are important differences when both control groups are compared. In order to make the results easier to discuss and understand, we have divided this section into different subsections according to the different possible comparisons performed in this study. In these subsections, major results are highlighted, however, in general feed restriction in the two breeds led to a shutdown of cellular mechanisms associated to milk production in agreement with studies by other authors [21].

\section{Breed effects under control situations}

This comparison suggests a high level of similarity between the mammary glands from both breeds when subjected to adequate nutritional levels. This is likely a consequence of a similar genetic background for the ancestors of the two breeds that include both Iberian and African goats that were at some point transported to the Canary Islands [22]. Nevertheless, there are interesting differences.

Genes showing differential expression include: POSTN and RNASE1 (over expression in $\mathrm{MC}$ ) and RGS4 (over expression in PC). Gene POSTN codes for the protein periostin, which is associated with cell growth in mammary tumors [23, 24], whereas RNASE1 signals for ribonuclease A family member 1 , a protein involved in milk production traits in dairy cattle by regulating protein synthesis and acting as a growth factor in epithelial cells in vitro [25]. Gene RGS4 codes for regulator of G protein signaling 4 . In humans, RGS4 is involved in the suppression of breast tumor initiation and progression [26], overall indicating a role in the suppression of cell 


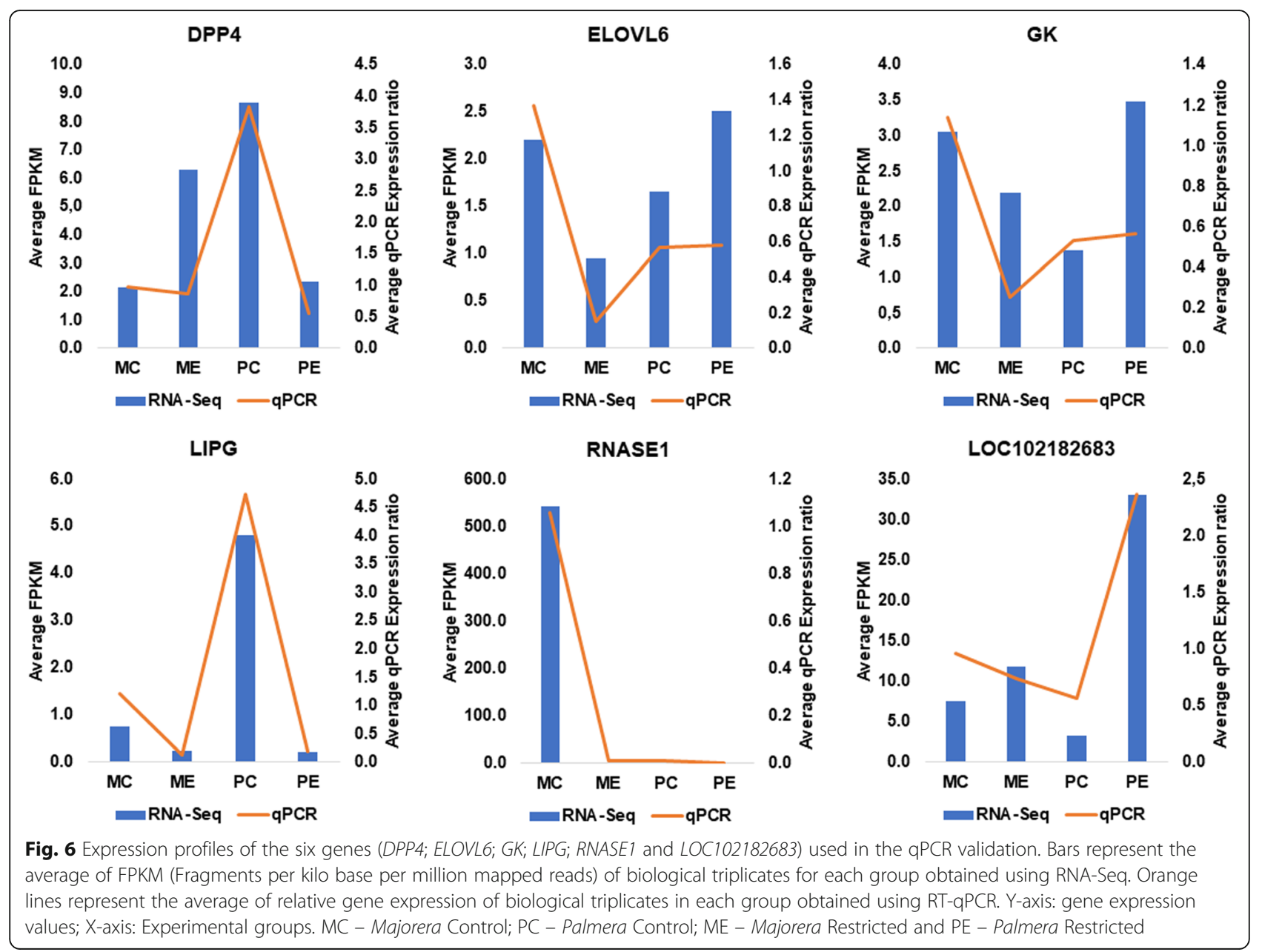

differentiation in sheep. Based on the evidence and considering that the animals were in a similar lactation stage, we can speculate that the MC group had higher mammary gland epithelial growth and differentiation than the PC group. This is likely a consequence of higher milk productions achieved by the Majorera breed [8].

\section{Major pathways affected by weight loss in the Majorera mammary gland transcriptome}

The Majorera mammary gland transcriptome was affected by feed restriction. The genes found to have differential expression are involved in a plethora of biological functions: from RNA processing to energy production, from amino acid transport and nucleotide transport to transcription or signal transduction; and from defense mechanisms to those with an unknown function.

Among the different DEGs involved in RNA processing, IGFBP6 is an interesting example, and this gene was down-regulated in the ME group. This protein inhibits Insulin Growth Factor which is a protein involved in reducing cell growth and apoptosis protection [27]. In general, these results were expected as a consequence of a slowdown in mammary transcriptional machinery, lowering cell differentiation and proliferation which in turn decreased milk yield. Similar results were observed by Ollier an co-workers [21] in feed deprived dairy goats. On the contrary, Bionaz and co-workers [28] and Palombo and co-workers [29] observed an increased expression of several genes involved in such pathways in the mammary glands of dairy cows and sows transitioning from late gestation to peak lactation, respectively.

We observed a downregulation of DEGs involved in the transport and synthesis of biological compounds likecarbohydrate ( $L A L B A$ or $G K$ for instance), lipid (TM7SF2 or ELOVL6) and amino acid (e.g. TONSL). These results are a consequence of the reduced metabolic activity of the mammary gland in the ME group when compared to the MC group in accordance with our previous results [8]. Therefore, feed restriction leads to decreases in the synthesis of carbohydrates or lipids in the mammary gland with severe consequences on milk production. Genes involved in these pathways are 


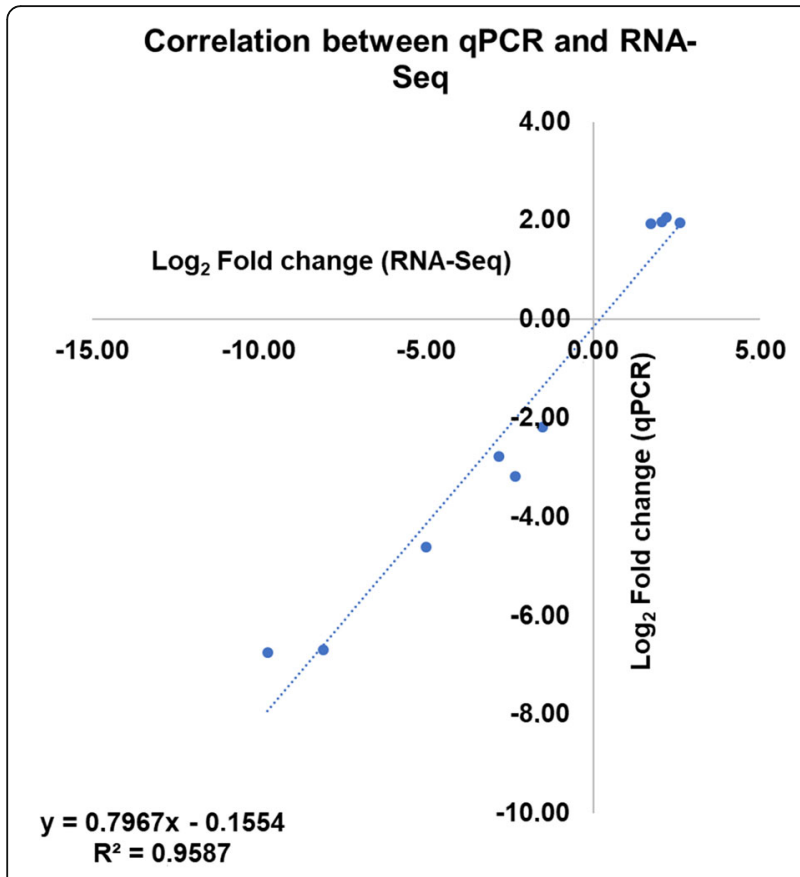

Fig. 7 Scatter plot with the $\log _{2}$ fold change observed in RNA-Seq and qPCR for the RNASE1, GK, ELOVL6, LIPG, DPP4 and LOC102182683 at the comparisons where the genes where considered DE in the RNA-Seq data

highly expressed in the mammary gland of dairy goats [30] as well as sheep and cattle [31] and are closely related to milk synthesis and secretion. Again, the pattern of results observed is consistent with studies on mammary gland transcriptomics that contrast for instance animals with different nutritional levels that lead to high or low milk yield [32-35].

The secondary metabolites biosynthesis, transport and catabolism pathway was up- regulated in the ME group as a consequence of weight loss. Two DEGs were described within this pathway: LOC102175938 and HSD17B11. The first, also known as cytochrome b-245 heavy chain [36] is involved in the AGE-RAGE signaling pathway in diabetic complications, being specifically involved in the non-enzymatic oxidation of proteins, lipids and nucleic acids. This gene is also involved in the NOD-like receptor signaling pathway, specifically through the generation of the innate immune response. Gene HSD17B11 codes for protein hydroxysteroid 17beta dehydrogenase, and this enzyme is crucial in diverse reproductive pathways in both males and females, regulating intracellular concentrations of inactive and active steroids [37]. It is interesting to point out also one gene in this category, LOC102191547 also refered to as cytochrome P450 2F3-like. This is a gene of the cytochrome P450 (CYP) enzyme family involved in steroid metabolism [38]. The over expression of both HSD17B11 and LOC102191547 is likely related to cell catabolism and a slowdown of steroid production resulting in the inhibition of mammary gland development [39] This is a common mechanism related to drying off. In this experiment, feed restriction could promote the activation of this mechanism and the decreased milk yield. Nevertheless, results obtained for LOC102191547 require further investigation.

Regarding the intracellular trafficking and vesicular transport pathways, $C X C R 4$ or $C-X-C$ motif chemokine receptor 4 is a gene that is associated specifically to the cytokine-cytokine receptor interaction, leukocyte transendothelial migration and chemokine signaling pathways [40] and is up-regulated in ME. Similarly, MSR1 or macrophage scavenger receptor 1 is related to phagocytosis [41], NKG7 codes for natural killer cell granule protein 7 and is involved in the immune response [42] and CD68 that codes for CD68 molecule protein is associated to the lysosome metabolism. All the genes are therefore involved in the modulation of the inflammatory response. This is likely a consequence of the shutdown and involution of the goat mammary gland, as demonstrated in dairy cows [43]. It seems therefore, that different inflammatory responses associated genes and proteins are up-regulated in the Majorera breed because of feed restriction. Considering the defense mechanisms pathway, gene SVEP1 is one of the various components of the immune response [44], whereas LOC102187241 codes for protein BPI fold containing family B member 1 , a protein of inflammatory response in the upper airway and the progression of non-small cell lung cancer in humans [45]. Such results are difficult to interprete and further studies are needed to better understand these results.

Regarding extracellular structures, gene OLFML3 codes for olfactomedin like 3, a protein associated with growth, proliferation and neovascularization [46]. Gene LGALS3 is a gene that codes for galectin 3, a protein over accumulated in mammary epithelial cells during mammary gland involution [47]. Given the involution of the mammary gland in the ME group, the latter results were expected, whereas the first gene being associated to growth is likely to have up-regulation in the MC group. Gene MT1MMP codes for matrix metallopeptidase 14, which is associated to mammary gland adipocyte differentiation [48]. It is therefore very surprising that it is upregulated in the ME group, and it is speculated that this gene may participate in other unknown pathways, as such, further research is still needed.

Regarding genes associated to cytoskeleton, ACTG2 and CNN1 code for actin gamma 2 and calponin 1, respectively. Both proteins are involved in smooth muscle contraction [49]. The up-regulation of such genes in the MC group may be a consequence of the higher metabolic activity and gland secretory function maintenance in this group. 
Several genes with unknown function were detected. This fact reflects the lack of information available in domestic animal databases, particularly for Capra hircus, which limits the research output [16]. Some of these genes coding for proteins involved in different diseases and physiological processes, particularly inflammatory reactions to certain types of human cancer. For instance, $A D A M D E C 1$, was up-regulated in the ME group. This gene codes for ADAM like decysin 1, a protein that plays an important role in cancer prevention [50] and intestinal inflammation in humans [51]. Gene HSD17B11 $[37,52]$ was also up-regulated in the ME group and was previously addressed. As many of these genes were upregulated in the ME group, it could be suggested that this increased the expression of genes regulating the immune response during SWL. Nevertheless, such interpretation, albeit interesting, is speculative and needs further investigation.

\section{Major pathways affected by weight loss in the Palmera mammary gland transcriptome}

Genes involved in lipid transport, carbohydrate transport, amino acid transport and nucleotide transport are in their majority up-regulated in the control group. Similalry to what was previously discussed for the Majorera groups, the Palmera mammary gland transcriptome was also affected by feed restriction. The several DEGs include COG terms such as RNA processing, amino acids transport and carbohydrates transport. It includes also translation, transcription, protein turnover, and signal transduction and finally genes with unknown. Function. Some of the results obtained are related to the mammary transcriptional machinery, particularly with the decrease in cell differentiation and proliferation, with a consequent and expectable lower expression in the restricted group.

Contrary to the results obtained in the Majorera groups (MC vs. ME), RNA processing and modification (e.g. F3), transcription (e.g. RGS1) and signal transduction (e.g. RARRES1) were up-regulated in the PE group. Overall, these results can be considered as un-expected. Indeed, the PE group showed a decreased activity in mammary transcriptional machinery, with lower levels of cell differentiation and proliferation as described for the whole mammary gland [21] and supported by our previous proteomics analysis [17] and similarly to analogous descriptions by other researchers [53]. Such response seems however to be dependent on the different tissues within the mammary gland, with clear differences between the fat pad and parenchymal tissue, with the latter showing a stabilization of similar COG terms and post-translational modification as a function of lower nutritional levels in Holstein heifers [43]. Our study focuses essentially on the secretory parenchymal tissue and not on the whole mammary gland. As such, further research is needed to enlighten the affected pathways, particularly considering the different subsections of the mammary gland and the variety of different tissues that are part of the organ.

Contrary to the what was observed for the Majorera breed, the expression pattern of genes involved in intracellular trafficking, secretion, and vesicular transport pathways are not evident in the Palmera groups comparison. Indeed, several DEGs are up-regulated (e.g. TRPM2 and CXCR2) and others down-regulated (GABRB1 and RELT) in the PE group compared to the PC group. Gene TRPM2 is involved in the NOD-like receptor signaling pathway of the immune response and is involved in cell proliferation [54], whereas CXCR2 is involved in the modulation of the chemokine signaling pathway and endocytosis. On the contrary, GABRB1 is involved in neurotransmission [55] and RELT in the immune response [56]. The two opposite tendencies in the gene expression could be a consequence of a major disruption of the two pathways. Such divergent tendencies have been recorded in mammary gland involution in dairy cows and water buffalo $[57,58]$.

The PE group showed an up-regulation of DEGs involved in the defense mechanisms (e.g. DUSP1, DUSP6 and LOC102190323). Gene DUSP is involved in the suppression of tumorigenic cell proliferation [59], a consequence of decreased cellular proliferation caused by the mammary gland involution. Gene LOC102190323 is involved in DNA damage response [60]. These results are in agreement with mammary gland transcriptome studies related to involution in goats [21] dairy cows [57] and water buffalo [58].

The extracellular structures pathways showed one DEG down-regulated (LOC100860938) and two DGEs up-regulated (MMP7 and MMP2) in the PE group. LOC100860938 or COL3A1 codes for collagen type III alpha 1 chain, a protein that is involved in the AGERAGE signaling pathway and in turn in cell proliferation [61], rendering these results expectable. Conversely, $M M P 2$ and MMP7 code for matrix metallopeptidases. These proteins, particularly $M M P 7$, are involved in cellular senescence [62], which agrees with the involution and lowering of different metabolic function in the mammary gland of Palmera breed.

The cytoskeleton term in the Palmera breed comparison returned MTAP2 and TMOD4, coding respectively for microtubule associated protein 2 (DEG up-regulated in the PE group) and tropomodulin 4 (DEG up-regulated in the PC group). Gene MTAP2 codes for proteins associated to autophagy in different tissues in the dromedary [63] and particularly during the involution of the bovine mammary gland [64]. Gene TMOD4 is poorly described and seems to be involved in adipogenesis, myogenesis and the regulation and myofibril assembly in the muscle [39]. 
Such roles may be extrapolated for the mammary gland, justifying our results.

\section{Major pathways affected in both feed restricted groups}

A comparison between the two reticted groups indicated several pathways with DEGs. These included for instance lipid metabolism, amino acid transport, nucleotide transport, among others. Similarly to the two previous comparisons, many are related to intracellular trafficking and energy metabolism. Gene GPD1 codes for glycerol-3-phosphate dehydrogenase 1, an enzyme involved in energy production, specifically lipid metabolism [65]. Similar lack of differences in the expression of this gene in the mammary gland of $\mathrm{Al}$ pine goats with different levels of lipid supplementation [66] or compared to hay-based diets [67] has also been described. Interestingly, Waldemarson and Karlsson [68] studied the activity of this enzyme in the mammary gland of the Mongolian gerbil (Meriones unguiculatus) and found it to be specifically associated to involution of the tissue. The fact that this gene is overexpressed in the PE group likely indicates a lower adaptation to SWL and an earlier onset of the mammary gland involution.

The amino acid transport pathway showed two DEGs overexpressed in the ME group (CPM and ASB11) compared to the PE group. Gene CPM codes for protein carboxypeptidase $\mathrm{M}$, a protein involved in different roles namely hematopoietic cell differentiation, neuronal development with particularly high levels during adipogenesis [69]. Gene ASB11 codes for protein ankyrin repeat and SOCS box containing 11. This protein has been found to be over-expressed in healthy compared to mastitic and involuting mammary glands in heifers [70]. Carbohydrates transport term only retrieved $S-L Z$ gene. This gene codes for protein serum lysozyme, a protein that has long been associated to mammary gland involution [71], specifically through the modulation of antioxidant activity [72]. Therefore, this gene could equally be proposed as a biomarker for SWL tolerance.

Associated to the nucleotide transport pathway, two DEGs were up-regulated (ENPP1 and LOC102191092) and one DEG was down-regulated (CTPS1) in the ME group. Gene ENPP1 codes for protein ectonucleotide pyrophosphatase/phosphodiesterase 1, involved in cell proliferation and differentiation in breast tumors in humans [73]. Gene LOC102191092 or CDA codes for protein cytidine deaminase, a protein related to DNA demethylation and expression of pluripotency genes in bovine cell differentiation [74, 75]. Both findings corroborate our results, highlighting higher cellular activity in the ME group compared to the PE group. On the contrary, CTPS1 codes for protein CTP synthase 1, a poorly studied protein that has however been associated to lymphocyte proliferation [76]. It could therefore be speculated that its down-regulation in the ME group compared to the PE group that could be associated with increased lymphocyte activity, associated in turn to an advanced involution status of the mammary gland in the latter. Gene ELOVL6 or ELOVL fatty acid elongase 6 is a gene involved in lipids transport, specifically in fatty acid elongation. Interestingly, this family of genes are down-regulated in the mammary gland of obese rats [77], which supports the results obtained in our study. From such pattern of expression and given the consistency of results, this gene may be suggested as a potential biomarker for SWL tolerance.

The transcription patway retrieved one DEG, while, the translation, ribosomal structure and biogenesis retrieved another DEG and finally the posttranslational modification, protein turnover, chaperones pathways retrieved 5 DEGs. The majority of these genes were upregulated in the $\mathrm{ME}$ group, which was expected, given the fact that the mammary gland of the Majorera breed clearly undergoes higher levels of cellular metabolism as previously detailed. On the contrary, NR4A1 and LOC102168230, which code for nuclear receptor subfamily 4 group A member 1 and alpha-2-glycoprotein 1, zinc-binding, respectively had higher expression in the $\mathrm{PE}$ group. The first protein is associated to oxidative stress and induced apoptosis in human fibroblasts [78], whereas the latter is related to apoptosis in human breast cancer [79]. The up-regulation of these two genes in the PE group is therefore likely related to a more exacerbated involution-induced apoptosis in these animals.

Associated to intracellular trafficking, secretion, and vesicular transport pathways, two DEGs were downregulated $(D A R C, S E L P)$ and one DEG was up-regulated (LOC102186944) in the PE group compared to the ME group. Gene $D A R C$ codes for atypical chemokine receptor 1 , which regulates the inflammatory response [80]. Gene SELP codes for selectin P, a protein that mediates and promotes leukocyte adhesion to endothelium, being essential for leukocyte recruitment to an infection site [81]. Gene LOC102186944 codes for allergen Bos d 2, a poorly studied protein, so far without any specific known described relation to the mammary gland physiology. These results are most likely a consequence of the higher inflammation and leukocyte activity levels in the mammary gland of the PE goats in order to more efficiently manage the mammary gland shutdown. Considering this pattern of expression, higher in the PE group, these genes could be suggested as potential markers for SWL tolerance, although further research is needed.

\section{Conclusions}

As a consequence of weight loss, different genes and pathways show altered expression during the experimental period. The research described in this work, illustrates that different pathways are affected by weight loss in the 
two dairy goat breeds (Majorera and Palmera), particularly regarding apoptosis, intracellular trafficking, transcription, as well as lipid and amino acid metabolism. As such, different genes are affected and of possible use in the establishment of markers to SWL, namely those implicated in tolerance (ENPP1,S-LZ) with higher accumulation in the ME group and susceptibility to SWL (GPD1, CTPS1, ELOVL6 and NR4A1) with higher accumulation in the PE group. This study unveiled potential candidate genes associated to SWL tolerance, which may impact lactation performance in goats. Based on this, these genes could be used as a reference in future breeding programs for SWL tolerance in dairy goats. Finally, results are likely to be extrapolated to other dairy species such as ewes, water buffaloes and dairy cattle.

\section{Methods}

Location, animals and nutritional treatments

As described, the animal experiment was performed at the Universidad de Las Palmas de Gran Canaria (Arucas, Gran Canaria, Spain) with animals supplied by the Pico Research Farm (Valle Guerra, Tenerife, Spain) [8]. Nine Majorera and ten Palmera goats, 3 lactations with kidding in late February were used [8]. Animals had a body condition score of three (1-5 scale) [8]. Animals were healthy during the whole trial that lasted 22 days [8]. All goats used in this trial were in peak lactation (approximately $50 \pm 15$ days in milk) [8].

The animals were divided at random into four groups, two per breed: control and feed restricted: MC - Majorera control $(n=4)$; ME - Majorera restricted $(n=5) ; \mathrm{PC}$ - Palmera control $(n=6)$; PE - Palmera restricted $(n=$ 4) [8]. Animals were milked as described [8, 31, 32]. Milk production per day and BW at the beginning of the trial were $1.60( \pm 0.47) \mathrm{l}$ and $45.5( \pm 7.74) \mathrm{kg}(\mathrm{MC}$ group), $1.68( \pm 0.25) \mathrm{l}$ and $50.6( \pm 3.64) \mathrm{kg}$ (ME group), $1.03( \pm 0.51) \mathrm{l}$ and $32.8( \pm 4.91) \mathrm{kg}$ (PC group) and 1.33 $( \pm 0.19) \mathrm{l}$ and $40.6( \pm 2.05) \mathrm{kg}$ (PE group) [8]. During the experimental period, animals were housed in two different pens, one for the control groups and one for the underfed groups [8]. A floor space of $1.7 \mathrm{~m}^{2}$ per animal was used [8]. Finally, goats had ad libitum access to drinking water [8]. To mimic field conditions of drought-prone regions under SWL, the following nutritional restrictions were used: $M E$ and PE goats were fed on wheat straw and a vitamin-mineral supplement that lead to a BW reduction of $15-20 \%$ [8]. On the contrary, $\mathrm{MC}$ and PC goats were fed an adequate diet in accordance with lactation requeriments following the INRA's (Institut National de la Recherche Agronomique) procedures sa detailed [8]. The experimental period was 22 days as this was the date when ME and PE goats had a stable $13-15 \%$ decrease in relative BW [8]. At day 22, BW and daily milk production were the following: 48.2 $\mathrm{kg}$ and $1.99 \mathrm{l}$ (MC group), $44.1 \mathrm{~kg}$ and $0.22 \mathrm{l}$ (ME group), $33.9 \mathrm{~kg}$ and $1.15 \mathrm{l}$ (PC group) and $35.4 \mathrm{~kg}$ and $0.17 \mathrm{l}$ (PE group) as previously described [8].

\section{Mammary gland sample collection}

As described [17, 18], goats were first sedated using an intravenous injection $(16 \mu \mathrm{g} / \mathrm{kg}$ of BW) of Xilagesic $20 \%$ (Calier, Barcelona, Spain) [17, 18]. The udder was then carefully cleaned and disinfected with a povidone-iodine solution [17, 18]. Prior to biopsy retrieval, local anesthesia was subcutaneously injected $(10 \mathrm{~mL}$ of $2 \%$ lidocaine, Lidocaina inyectable 2\%, Braun, Barcelona, Spain) to the biopsy collection area $[17,18]$. Approximately ten minutes later, a $2 \mathrm{~mm}$ incision (left half udder) was made using a scalpel blade (Braun, Tuttingen, Germany) and biopsies collected [17, 18]. The mammary gland was finally sutured and prophylactic treatment administered as described $[17,18]$.

Biopsy samples (1.5-2 g tissue) were then rinsed in sterile PBS, snap frozen in liquid nitrogen and stored at $80^{\circ} \mathrm{C}$ until further analysis [17, 18]. A total of three samples per group were chosen at random and used in subsequent transcriptomics analysis, similarly to what was previously described [17]. This number of samples is considered as a minimum for a transcriptomics analysis and has been used by other researchers conducting work on the subject [82]. Animal experimental procedures were in accordance with international rules and regulations (European Union procedures on animal experimentationDirective 2010/63/EU) as described and the protocol was approved by the Universidad de Las Palmas de Gran Canaria Ethics committee [17, 18]. Finally, goats used were housed and fed in conditions similar to those used by goat farms in the Canary Islands.

\section{Tissue mRNA isolation and cDNA synthesis}

Total RNA was extracted from the tissue using the E.Z.N.A. Total RNA Kit II (Omega Bio-Tek Inc., Norcross, Georgia, USA). About $30 \mathrm{mg}$ of tissue was finely ground in liquid nitrogen and used with the kit following manufacturer's instruction to extract total RNA. A DNAse digestion step was carried out after extraction to remove contaminating genomic DNA using an Ambion ${ }^{\odot}$ TURBO $^{\mathrm{Tm}}$ DNase (Life Technologies, Carlsbad, CA, U.S.A.) following manufacturer's instructions. A quantitative and qualitative assessment of the isolated RNA was performed using a NanoDrop ${ }^{\circledR}$ 2000c Spectrophotometer (Thermo Fisher Scientific Inc., Waltham, MA, U.S.A.). Purity was estimated based on the absorbance ratios of the RNA samples at $260 / 280 \mathrm{~nm}$ and $260 / 230 \mathrm{~nm}$. For both ratios, values were close to 2 (for all samples average 260/280 $\mathrm{nm}$ and average 260/230 nm of 1.96 and 1.88 respectively). RNA quality and integrity was also analysed using a RNA Nano Kit Chips from the Agilent 2100 Bioanalyzer System 
(Agilent Technologies, Santa Clara, CA, U.S.A.). All samples sent to sequencing had a RNA Integrity Number (RIN) above 7. The absence of DNA in RNA treated samples was verified by standard polymerase chain reaction (PCR).

\section{Next generation sequencing, statistical and bioinformatic analysis}

RNA Sequencing was conducted by LC-Sciences (Houston, TX, USA). Twelve mRNA libraries were constructed, 3 biological replicates per condition, following the experimental scheme previously described. Briefly, Poly(A) selection was used and a 100 cycle paired end read was performed using Illumina HiSeq 2500 technology, following the TruSeq ${ }^{\circ}$ Stranded mRNA Sample Preparation Guide (Illumina). Raw sequencing data can be found in the availability of data and materials section. They were deposited in the NCBI GEO under the accession number GSE151599 and available at: https://www.ncbi.nlm.nih.gov/geo/query/acc.cgi?acc= GSE151599. Data was analyzed using the Capra hircus (goat) reference genome, version CHIR_1.0 and available at: https://www.ncbi.nlm.nih.gov/assembly/GCF_000317765.1/ . The software default settings were defined using RSEM (v1.2.17, http://deweylab.biostat.wisc.edu/rsem/) to estimate transcript abundance based on fragments per kilobase per transcript per million mapped reads (FPKM), edgeR (v3.2.4) to assess the differentially expressed genes, http:// www.bioconductor.org/packages/release/bioc/html/edgeR. html) and Bowtie2 (v2.2.3, http://bowtie-bio.sourceforge. net/bowtie2/index.shtml) used for mapping of the sequences. Categorization of the expressed genes by orthologous groups was performed using Cluster of Orthologous Groups (COG; e-Value 1e-3) within Blast2GO (version 5) with the coding sequence of each transcript. Genes were considered expressed when the raw number counts were at least 100 in at least one sample. Statistical significance was defined as $p$-value $<0.05$ (t-test); False Discovery Rate (FDR), calculated using the Benjamini-Hochberg test, below 0.05 and Log2 Fold change (FC) above 1.5 or below -1.5 . The $\log _{2}$ fold change for RNA-Seq was calculated using edgeR. Principal components analysis (PCA) was performed on the expression values obtained for the differentially expressed genes between at least two experimental conditions using the software Statistica, version 6 (Statsoft). Before computation, value of fragment per kilobase million (FPKM) were $\log _{2}$ transformed. Heatmaps were obtained via Multiple Experiment Viewer (https://mev.tm4.org; accessed on the 16th of May 2018), Average Linkage Criteria Algorithm and Distance Metric: Pearson, using the $\log _{2}$ FPKM of the DEGs per comparison established.

\section{Primer design for RT-qPCR experiments}

Six candidate genes were selected based on their differential expression results. Primers for candidate genes were constructed: C. hircus lipase, endothelial (LIPG) (NCBI Gene ID: 102191574), C. hircus ELOVL fatty acid elongase 6 (ELOVL6) (NCBI Gene ID: 102181762), C. hircus glycerol kinase (GK) (NCBI Gene ID: 102170215), C. hircus dipeptidyl-peptidase 4 (DPP4) (NCBI Gene ID: 102184205), C. hircus growth-regulated alpha proteinlike (LOC102182683) (NCBI Gene ID: 102182683) and C. hircus ribonuclease, RNase A family, 1 (pancreatic) (RNASE1) (NCBI Gene ID: 102174664).

Primer sequences were designed within the coding regions of the target genes from Capra hircus genome (CHIR_1.0, annotation release 100) using Primer3 Plus (http://www.bioinformatics.nl/cgi-bin/primer3plus/primer3 plus.cgi) and the with selection settings (size 18-22 base pairs (bp); annealing temperature (Tm) $57-63^{\circ} \mathrm{C}$; GC percentage $50-60 \%$ ) and a PCR product length of 75-150 bp. Primer synthesis was performed by StabVida (ITQB NOVA, Oeiras, Portugal). Primer sequences are detailed in Supplementary material 8.

\section{Reverse-transcribed quantitative PCR (RT-qPCR)}

Messenger RNA was reverse transcribed into cDNA using Oligo(dT) primers included in Promega ImProm$\mathrm{II}^{\mathrm{tm}}$ Reverse Transcription System (Promega, Madison, WI, USA) according to the manufacturer's instructions. One microgram of total RNA per sample was used and three biological replicates per condition (control and restricted groups of both breeds) were reverse transcribed.

The $\mathrm{qPCR}$ reactions were performed in a PikoReal Real-Time PCR System (Thermo Fisher Scientific Inc., Waltham, MA, U.S.A.) to measure levels of transcripts of the reference genes. The reaction mixture consisted of $0.2 \mu \mathrm{l}$ of each $10 \mathrm{mM}$ primer, $5 \mu \mathrm{L}$ of $2 \mathrm{x} \mathrm{SYBR}^{\circ}$ Green Real-time PCR Master Mix (Bio-Rad Laboratories Inc., Hercules, CA, U.S.A.), $1 \mathrm{ng}$ of the each reverse transcribed cDNA and autoclaved Milli-Q water to a final volume of $10 \mu \mathrm{L}$. Reactions were performed in duplicate with a non-template control, on 96-well optical reaction plates. The qPCR programme consisted of an initial incubation step at $95^{\circ} \mathrm{C}$ for five min, amplifications were performed for 40 cycles with the following cycle profile: a denaturing step at $95^{\circ} \mathrm{C}$ for $10 \mathrm{~s}$ followed by an annealing step at $60^{\circ} \mathrm{C}$ for $30 \mathrm{~s}$. The specificity of the qPCR products was confirmed through a melting temperature analysis from $55^{\circ} \mathrm{C}$ to $95^{\circ} \mathrm{C}$ in $0.2^{\circ} \mathrm{C}$ intervals. The melting curve obtained was analyzed to confirm the presence of a single gene-specific peak and the total absence of primer-dimers. The GenEx Pro software (GenEx Pro 4.3.7, MultiD Analyses AB, Göteborg, Sweden), which includes in its pipeline for data analysis the NormFinder [83] and geNorm [84] algorithm, was used to identify the most stable reference genes.

For each primer pair the efficiency of the reaction and slope values were determined using LinReg Software 
(v2013.0) based on previously published work [85]. All data, including the cycle threshold $(\mathrm{Cq})$ obtained through LinReg Software were used for the delta $\mathrm{Ct}$ method [86]. Relative gene expression of candidate genes was calculated using the delta $\mathrm{Ct}$ method with two reference genes beta-actin $(A C T B)[87,88]$ and elongation factor 1 alpha 1 (EEF1A1). Please refer to supplementary material 8 for additional details on RT-qPCR results.

\section{Supplementary information}

Supplementary information accompanies this paper at https://doi.org/10. 1186/s12864-020-06968-2.

Additional file 1. Raw read counts for all genes and all samples in the study.

Additional file 2. List of differentially expressed genes between Majorera Control vs. Palmera Control. The $\log _{2}$ Fold Change $\left(\log _{2} \mathrm{FC}\right)$, $\log _{2}$ of counts per million ( $\log _{2}$ Counts), calculated $P$-value and FDR is shown. Raw reads for each gene in each sample are described: Majorera Control (MC1, MC2 and MC3) and Palmera Control (PC1, PC2 and PC3).

Additional file 3. List of differentially expressed genes between Majorera Control vs. Majorera Restricted. The $\log _{2}$ Fold Change ( $\left.\log _{2} \mathrm{FC}\right)$, $\log _{2}$ of counts per million ( $\log _{2}$ Counts), calculated $P$-value and FDR is shown. Raw reads for each gene in each sample are described: Majorera Control (MC1, MC2 and MC3) and Majorera Restricted (ME1, ME2 and ME3).

Additional file 4. List of differentially expressed genes between Palmera Control vs. Palmera Restricted. The $\log _{2}$ Fold Change ( $\left.\log _{2} F C\right), \log _{2}$ of counts per million ( $\log _{2}$ Counts), calculated $P$-value and FDR is shown. Raw reads for each gene in each sample are described: Palmera Control (PC1, PC2 and PC3) and Palmera Restricted (PE1, PE2 and PE3).

Additional file 5. - List of differentially expressed genes between Majorera Restricted vs. Palmera Restricted. The $\log _{2}$ Fold Change ( $\log _{2} \mathrm{FC}$ ), $\log _{2}$ of counts per million ( $\log _{2}$ Counts), calculated P-value and FDR is shown. Raw reads for each gene in each sample are described: Majorera Restricted (ME1, ME2 and ME3) and Palmera Restricted (PE1, PE2 and PE3).

Additional file 6. All genes expressed in the study, with respective FPKM (Fragments per kilo base per million mapped reads) value in each sample.

Additional file 7. Tables summarizing the orthologous groups for each DE gene found in the main comparisons established (obtained via Blast2GO, Cluster of orthologs e-Value 1e-3).

Additional file 8. - Details of the primers built for reference and candidate genes to be used in RT-qPCR, expression values from RNA-Seq and GPCR used for expression profiling and correlation analysis.

Additional file 9. - Output of the edgeR analysis for the Majorera Control and Majorera Restricted comparison. The $\log _{2}$ Fold Change ( $\left.\log _{2} \mathrm{FC}\right), \log _{2}$ of counts per million ( $\log _{2}$ Counts), calculated $P$-value and FDR is shown. Raw reads for each gene in each sample are described: Majorera Control (MC1, MC2 and MC3) and Majorera Restricted (ME1, ME2 and ME3). NCBI gene and transcripts IDs are provided. Only genes with $\log _{2} \mathrm{FC}>0.5$ or $\log _{2} \mathrm{FC}<0.5$ are provided.

Additional file 10. - Output of the edgeR analysis for the Palmera Control and Palmera Restricted comparison. The $\log _{2}$ Fold Change ( $\left.\log _{2} \mathrm{FC}\right), \log _{2}$ of counts per million (Log 2 Counts), calculated P-value and FDR is shown. Raw reads for each gene in each sample are described: Palmera Control (PC1, PC2 and PC3) and Palmera Restricted (PE1, PE2 and PE3). NCBI gene and transcripts IDs are provided. Only genes with $\log _{2} F C>0.5$ or $\log _{2} F C<0.5$ are provided.

Additional file 11 - Output of the edgeR analysis for the Majorera Control and Palmera Control groups comparison. The $\log _{2}$ Fold Change
( $\left.\log _{2} F C\right), \log _{2}$ of counts per million ( $\log _{2}$ Counts), calculated P-value and FDR is shown. Raw reads for each gene in each sample are described: Majorera Control (MC1, MC2 and MC3) and Palmera Control (PC1, PC2 and $P(3)$. NCBI gene and transcripts IDs are provided. Only genes with $\log _{2} \mathrm{FC}>0.5$ or $\log _{2} \mathrm{FC}<0.5$ are provided.

Additional file 12 - Output of the edgeR analysis for the Majorera Restricted and Palmera Restricted groups comparison. The $\log _{2}$ Fold Change ( $\log _{2} \mathrm{FC}$ ), $\log _{2}$ of counts per million (Log 2 Counts), calculated Pvalue and FDR is shown. Raw reads for each gene in each sample are described: Majorera Restricted (ME1, ME2 and ME3) and Palmera Restricted (PE1, PE2 and PE3). NCBI gene and transcript IDs are provided. Only genes with $\log _{2} \mathrm{FC}>0.5$ or $\log _{2} \mathrm{FC}<0.5$ are provided.

\section{Abbreviations}

ACTB: Actin beta; ACTG2: Actin gamma 2; ADAMDEC1: ADAM like decysin 1; AGE-RAGE: Advanced glycation end products - receptor for advanced glycation end products; ASB11: Ankyrin repeat and SOCS box containing 11; BW: Liveweight; CD68: CD68 molecule; CDA: Cytidine deaminase; CNN1: Calponin 1; COG: Cluster of Gene Ontology; CPM: Carboxypeptidase M; CSN1S2: Alpha 2-casein; CSN2: Casein beta; CSN3: Casein kappa; CTPS1: CTP synthase 1; CXCR2: C-X-C motif chemokine receptor 2; CXCR4: C-X-C motif chemokine receptor 4; CYP: Cytochrome P450; DARC: Atypical chemokine receptor 1; DEG: Differentially Expressed Genes; DPP4: Dipeptidyl peptidase 4; DUSP1: Dual specificity phosphatase 1; DUSP6: Dual specificity phosphatase 6; EEF1A1: Eukaryotic translation elongation factor 1 alpha 1; ELOVL6: ELOVL fatty acid elongase 6; ENPP1: Ectonucleotide pyrophosphatase/ phosphodiesterase 1; FC: Fold Change; FDR: False Discovery Rate; FPKM: Fragments per kilobase per million mapped reads; GABRB1: Gammaaminobutyric acid type A receptor subunit beta1; GK: Glycerol kinase; GPD1: Glycerol-3-phosphate dehydrogenase 1; HCl: Chloride Hydrogen; HSD17B11: Hydroxysteroid 17-beta dehydrogenase 11; IGFBP6: Insulin like growth factor binding protein 6; LALBA: Lactalbumin alpha; LGALS3: Galectin 3; LIPG: Lipase G, endothelial type; MC: Majorera Control; ME: Majorera Restricted; MMP2: Matrix metallopeptidase 2; MMP7: Matrix metallopeptidase 7; MSR1: Macrophage scavenger receptor 1; MT1MMP: Matrix metallopeptidase 14; MTAP2: Microtubule associated protein 2; NGEF: Neuronal guanine nucleotide exchange factor; NKG7: Natural killer cell granule protein 7; NR4A1: Nuclear receptor subfamily 4 group A member 1; OLFML3: Olfactomedin like 3; PAEP: Progestagen-associated endometrial protein; PC: Palmera Control; PCA: Principal Component Analysis; PE: Palmera Restricted; Pl16: Peptidase inhibitor 16; POSTN: Periostin; RARRES1: Retinoic acid receptor responder 1; RELT: RELT TNF receptor; RFX4: Regulatory factor X4; RGS1: Regulator of G protein signaling 1; RGS4: Regulator of G protein signaling 4; RNASE1: Ribonuclease pancreatic-like; RNA-Seq: RNA sequencing; SELP: Selectin P; S-LZ: Serum lysozyme; SPTLC3: Serine palmitoyltransferase long chain base subunit 3; SVEP1: Sushi, von Willebrand factor type A, EGF and pentraxin domain containing 1; SWL: Seasonal weight loss; TM7SF2: Transmembrane 7 superfamily member 2; TMOD4: Tropomodulin 4; TONSL: Tonsoku like, DNA repair protein; TP53INP2: Tumor protein p53 inducible nuclear protein 2; TRPM2: Transient receptor potential cation channel subfamily $\mathrm{M}$ member 2

\section{Acknowledgements}

Authors acknowledge Jorge Paiva (Polish Academy of Sciences, Poznan, Poland) for the consultancy and collaboration in designing this work.

\section{Authors' contributions}

SSA, JC, AA, NC and AMA conceived and designed the study. LHC, NC, AA and AMA conducted the animal experiment and mammary gland sample collection. JRP and SSA carried out RNA extraction. JRP, SSA and AMA conducted RNA-Seq bioinformatic and gene expression analyses. JRP, SSA and AMA conducted and analyzed qPCR results. JRP, LHC, SSA and AMA interpreted gene expression results. JRP, LHC, NC, SSA and AMA wrote the manuscript. All authors read, edited and approved the final version of the manuscript.

\section{Authors' information}

Not applicable 


\section{Funding}

This research was funded by by Fundação para a Ciência e Tecnologia (FCT, Lisbon, Portugal), through research project PTDC/CVT/116499/2010. Author JR Parreira and SS Araújo acknowledge respectively a PhD grant from Plants for life (PD/BD/113474/2015), PhD holder contract (DL57), and the research unit program GREEN-it: Bioresources for Sustainability" (UID/Multi/04551/ 2020) for Research infrastucture, all from the FCT. Author AM Almeida acknowledges funding from research unit program LEAF - Linking Landscape, Environment, Agriculture And Food Research Centre (ISA University of Lisbon) also funded by the FCT strategic project (UID/AGR/ 04129/2020) for Research infrastructure. Author Lorenzo E. HernándezCastellano acknowledges financial support from the Faculty of Science and Technology (Aarhus University, Denmark) for Research infrastructure. Authors were members of COST actions FA1002 - Proteomics in Farm Animals and FA1308 - Dairycare to whom networking funding is acknowledged. The funding agencies of this study had no role in the design of the study, data collection and analysis, interpretation of data, the decision to submit the report for publication or preparation of the manuscript.

\section{Availability of data and materials}

Data was analyzed using the Capra hircus (goat) reference genome, by the International Goat Genome Consortium, version CHIR_1.0 and available at: https://www.ncbi.nlm.nih.gov/assembly/GCF_000317765.1/.

All data in this study are included in the article and additional files. Raw read values for all samples obtained using RNA-Seq are available in Supplementary Material 1, the FPKM values for all genes are available in Supplementary Material 6, edgeR analysis outputs are available in supplementary material 9, 10, 11 and 12 .

Raw sequencing data were deposited in the NCBI GEO under the accession number GSE151599 (https://www.ncbi.nlm.nih.gov/geo/query/acc.cgi?acc=GSE1515 99), including the samples Majorera Control 1 (GSM4586432), Majorera Control 2 (GSM4586433), Majorera Control 3 (GSM4586434), Majorera Restricted 1 (GSM4586437), Majorera Restricted 2 (GSM4586435), Majorera Restricted 3 (GSM4586436), Palmera Control 1 (GSM4586438), Palmera Control 2 (GSM4586439), Palmera Control 3 (GSM4586440), Palmera Restricted 1 (GSM4586441), Palmera Restricted 2 (GSM4586442) and Palmera Restricted 3 (GSM4586443).

\section{Ethics approval and consent to participate}

Animal experimentation was conducted following pertaining EU and Spanish guidelines (2010/63/EU Directive). This experimental procedure was approved by the Ethics Committee of the Universidad de Las Palmas de Gran Canaria (1st Process 2012) and conducted under veterinary observation. Goat housing, husbandry and feeding were very similar to those in practice in local dairy goat farms.

\section{Consent for publication}

Not applicable.

\section{Competing interests}

Authors declare no competing interests.

\section{Author details}

${ }^{1}$ IBET - Instituto de Biologia Experimental e Tecnológica, Av. da República, 2780-157 Oeiras, Portugal. ${ }^{2}$ ITQB NOVA - Instituto de Tecnologia Química e Biológica António Xavier, Universidade Nova de Lisboa, Av. da República, 2780-157 Oeiras, Portugal. 'Department of Animal Science, AU-Foulum, Aarhus University, 8830 Tjele, Denmark. ${ }^{4}$ Animal Production and Biotechnology group, Institute of Animal Health and Food Safety, Universidad de Las Palmas de Gran Canaria, 35413 Arucas, Spain. ${ }^{5}$ Unit of Animal Production, Pasture, and Forage in Arid and Subtropical Areas, Canary Islands Institute for Agricultural Research, 38270 La Laguna, Spain. 'EAF Linking Landscape, Environment, Agriculture And Food, Instituto Superior de Agronomia, Universidade de Lisboa, Tapada da Ajuda, 13409-017 Lisbon, Portugal.

Received: 20 January 2020 Accepted: 3 August 2020 Published online: 14 September 2020

\section{References}

1. Cardoso LA, Almeida AM. Seasonal weight loss - an assessment of losses and implications on animal welfare and production in the tropics: southern
Africa and Western Australia as case studies. In: Harinder Makar PS, editor. Enhancing animal welfare and farmer income through strategic animal feeding. Rome: FAO; 2013. p. 37-44.

2. De Almeida AM, Cardoso LA. Animal production and genetic resources in Guinea Bissau: I - northern Cacheu Province. Trop Anim Health Prod. 2008; 40:529-36.

3. De Almeida AM, Cardoso LA. Animal production and genetic resources in Guinea Bissau: II - Tombali Province. Trop Anim Health Prod. 2008; 40:537-43.

4. Almeida AM, Schwalbach LM, de Waal HO, Greyling JP, Cardoso LA. The effect of supplementation on productive performance of Boer goat bucks fed winter veld hay. Trop Anim Health Prod. 2006;38:443-9.

5. Almeida AM, Schwalbach LMJ, Cardoso LA, Greyling JPC. Scrotal, testicular and semen characteristics of young Boer bucks fed winter veld hay: the effect of nutritional supplementation. Small Rumin Res. 2007;73:216-20.

6. Scanlon TT, Almeida AM, Van Burgel A, Kilminster T, Milton J, Greeff JC, Oldham C. Live weight parameters and feed intake in Dorper, Damara and Australian Merino lambs exposed to restricted feeding. Small Ruminant Res. 2013;109:101-6.

7. Almeida AM, Kilminster T, Scanlon T, Araújo SS, Milton J, Oldham C, Greeff JC. Assessing carcass and meat characteristics of Damara, Dorper and Australian merino lambs under restricted feeding. Tropical Animal Heath and Production. 2013:45:1305-11.

8. Lerias JR, Hernández-Castellano LE, Morales-Delanuez A, Araújo SS, Castro N, Argüello A, Capote J, Almeida AM. Body live weight and milk production parameters in the Majorera and Palmera goat breeds from the Canary Islands: influence of weight loss. Trop Anim Health Prod. 2013;45:1731-6.

9. Lerias JR, Peña R, Hernández-Castellano LE, Capote J, Castro N, Argüello A, Araújo SS, Saco Y, Bassols A, Almeida AM. Establishment of the biochemical and endocrine blood profiles in the Majorera and Palmera dairy goat breeds: the effect of feed restriction. J Dairy Res. 2015;82:416-25.

10. Herrera RG, Puyol DG, Martín EH, Presa LG, Rodríguez P. Influence of the North Atlantic oscillation on the Canary Islands precipitation. J Clim. 2001; 14:3889-903.

11. Fresno MR, Gomez J, Molina A, Darmanin N, Capote JF, Delgado JV. Preliminary study of the Majorera milk goat productive performance. Archivos de Zootecnia. 1994;43:181-6.

12. Escuder A, Fernandez G, Capote J. Characterization of the Palmera dairy goat production systems. Options Mediterraneenes. 2006;70:95-100.

13. Wickramasinghe $S$, Cánovas A, Rincón G, Medra JF. RNA-sequencing: a tool to explore new frontiers in animal genetics. Livest Sci. 2014;166:206-16.

14. Parreira JR, Araújo SS. Studying the animal transcriptome: state of the art and challenges in the context of animal and veterinary sciences. In: Almeida AM, Eckersall D, Miller I, editors. In Proteomics in Domestic Animals: from Farm to Systems Biology. Heidelberg: Springer; 2018. p. 421-46.

15. Almeida AM, Bassols A, Bendixen E, Bhide M, Ceciliani F, Cristobal S, Eckersall PD, Hollung K, Lisacek F, Mazzucchelli G, McLaughlin M, Miller I, Nally JE, Plowman J, Renaut J, Rodrigues P, Roncada P, Staric J, Turk R. Animal board invited review: advances in proteomics for animal and food sciences. Animal. 2015;9:1-17.

16. Ferreira AM, Bislev SL, Bendixen E, Almeida AM. The mammary gland in domestic ruminants: a systems biology perspective. J Proteomics. 2013;94: 110-23.

17. Hernández-Castellano LE, Ferreira AM, Nanni P, Grossmann J, Argüello A, Capote J, Cai G, Lippolis J, Castro N, de Almeida AM. The goat (Capra hircus) mammary gland secretory tissue proteome as influenced by weight loss: a study using label free proteomics. J Proteomics. 2016;145:60-9.

18. Cugno G, Parreira JR, Ferlizza E, Hernández-Castellano LE, Carneiro M, Renaut J, et al. The Goat (Capra hircus) Mammary Gland Mitochondrial Proteome: A Study on the Effect of Weight Loss Using Blue-Native PAGE and Two-Dimensional Gel Electrophoresis. PLoS One. 2016;1:e0151599.

19. Palma M, Hernández-Castellano LE, Castro N, Arguëllo A, Capote J, Matzapetakis M, de Almeida AM. NMR-metabolomics profiling of mammary gland secretory tissue and milk serum in two goat breeds with different levels of tolerance to seasonal weight loss. Mol BioSyst. 2016;12:2094-107.

20. Palma M, Alves SP, Hernández-Castellano LE, Capote J, Castro N, Argüello A, Matzapetakis M, Bessa RJB, de Almeida AM. Mammary gland and milk fatty acid composition of two dairy goat breeds under feed-restriction. J Dairy Res. 2017:84:264-71.

21. Ollier S, Robert-Granié C, Bernard L, Chilliard Y, Leroux C. Mammary transcriptome analysis of food-deprived lactating goats highlights genes 
involved in milk secretion and programmed cell death. J Nutr. 2007 137:560-7.

22. Amills M, Capote J, Tomàs A, Kelly L, Obexer-Ruff G, Angiolillo A, Sanchez A. Strong phylogeographic relationships among three goat breeds from the Canary Islands. J Dairy Res. 2004;71:257-62.

23. Haertel-Wiesmann M, Liang Y, Fantl WJ, Williams LT. Regulation of cyclooxygenase-2 and periostin by Wnt-3 in mouse mammary epithelial cells. Journal of Bilogical Chemistry. 2000;275:32046-51.

24. Shao R, Bao S, Bai X, Blanchette C, Anderson RM, Dang T, Gishizky ML, Marks $J R$, Wang XF. Acquired expression of periostin by human breast cancers promotes tumor angiogenesis through up-regulation of vascular endothelial growth factor receptor 2 expression. Molecular Cell Biol. 2004; 24:3992-4003

25. Raven LA, Cocks BG, Pryce JE, Cottrell JJ, Hayes BJ. Genes of the RNASE5 pathway contain SNP associated with milk production traits in dairy cattle. Genet Sel Evol. 2013;45:25.

26. Maity B, Stewart A, O'Malley Y, Askeland RW, Sugg SL, Fisher RA. Regulator of $\mathrm{G}$ protein signaling 6 is a novel suppressor of breast tumor initiation and progression. Carcinogenesis. 2013;34:1747-55.

27. Baxter RC. Insulin-like growth factor (IGF)-binding proteins: interactions with IGFs and intrinsic bioactivities. Am J Physiol Endocrinol Metab. 2000;278: E967-76.

28. Bionaz M, Periasamy K, Rodriguez-Zas SL, Everts RE, Lewin HA, Hurley WL, Loor JJ. Old and new stories: revelations from functional analysis of the bovine mammary transcriptome during the lactation cycle. PLoS One. 2012; 7:e33268.

29. Palombo V, Loor JJ, D'Andrea M, Vailati-Riboni M, Shahzad K, Krogh U, Theil PK. Transcriptional profiling of swine mammary gland during the transition from colostrogenesis to lactogenesis using RNA sequencing. BMC Genomics. 2018;19:322.

30. Shi H, Zhu J, Luo J, Cao W, Shi H, Yao D, Li J, Sun Y, Xu H, Yu K, Loor JJ. Genes regulating lipid and protein metabolism are highly expressed in mammary gland of lactating dairy goats. Funct Integr Genomics. 2015;15: 309-21

31. Singh M, Thomson PC, Sheehy PA, Raadsma HW. Comparative transcriptome analyses reveal conserved and distinct mechanisms in ovine and bovine lactation. Funct Integr Genomics. 2013;13:115-31.

32. Ollier S, Leroux C, de la Foye A, Bernard L, Rouel J, Chilliard Y. Whole intact rapeseeds or sunflower oil in high-forage or high-concentrate diets affects milk yield, milk composition, and mammary gene expression profile in goats. J Dairy Sci. 2009;92: 5544-60.

33. Ouattara B, Bissonnette N, Duplessis M, Girard CL. Supplements of vitamins B9 and B12 affect hepatic and mammary gland gene expression profiles in lactating dairy cows. BMC Genomics. 2016;17:640.

34. Dai W, Wang Q, Zhao F, Liu J, Liu H. Understanding the regulatory mechanisms of milk production using integrative transcriptomic and proteomic analyses: improving inefficient utilization of crop by-products as forage in dairy industry. BMC Genomics. 2018;19:403.

35. Faulconnier $Y$, Chilliard $Y$, Torbati MB, Leroux C. The transcriptomic profiles of adipose tissues are modified by feed deprivation in lactating goats. The transcriptomic profiles of adipose tissues are modified by feed deprivation in lactating goats. Comp Biochem Physiol Part D Genomics Proteomics. 2011;6:139-49.

36. Cassatella MA, Hartman L, Perussia B, Trinchieri G. Tumor necrosis factor and immune interferon synergistically induce cytochrome b-245 heavy-chain gene expression and nicotinamide-adenine dinucleotide phosphate hydrogenase oxidase in human leukemic myeloid cells. J Clin Invest. 1989; 83:1570-9.

37. Marchais-Oberwinkler S, Henn C, Möller G, Klein T, Negri M, Oster A, Spadaro A, Werth R, Wetzel M, Xu K, et al. 17ß-Hydroxysteroid dehydrogenases (17ß-HSDs) as therapeutic targets: protein structures, functions, and recent progress in inhibitor development. I Steroid Biochem Mol Biol. 2011;125:66-82

38. Mikolić A, Karačonji IB. Imidacloprid as reproductive toxicant and endocrine disruptor: investigations in laboratory animals. Arh Hig Rada Toksikol. 2018; 69:103-8.

39. Zhao X, Huang Z, Liu X, Chen Y, Gong W, Yu K, Qin L, Chen H, Mo D. The switch role of the Tmod4 in the regulation of balanced development between myogenesis and adipogenesis. Gene. 2013;532:263-71.

40. Wang Y, Dembowsky K, Chevalier E, Stüve P, Korf-Klingebiel M, Lochner M, Napp LC, Frank H, Brinkmann E, Kanwischer A, et al. C-X-C motif chemokine receptor 4 blockade promotes tissue repair after myocardial infarction by enhancing regulatory $T$ cell mobilization and immune-regulatory function. Circulation. 2019;139:1798-812.

41. Kong FQ, Zhao SJ, Sun P, Liu H, Jie J, Xu T, Xu AD, Yang YQ, Zhu Y, Chen J, et al. Macrophage MSR1 promotes the formation of foamy macrophage and neuronal apoptosis after spinal cord injury. J Neuroinflammation. 2020;17:62.

42. Peñagaricano F, Souza AH, Carvalho PD, Driver AM, Gambra R, Kropp J, Hackbart KS, Luchini D, Shaver RD, Wiltbank MC, Khatib H. Effect of maternal methionine supplementation on the transcriptome of bovine preimplantation embryos. PLoS One. 2013;8(8):e72302.

43. Piantoni P, Daniels KM, Everts RE, Rodriguez-Zas SL, Lewin HA, Hurley WL, Akers RM, Loor JJ. Level of nutrient intake affects mammary gland gene expression profiles in preweaned Holstein heifers. J Dairy Sci. 2012;95:2550-61.

44. Dahmer MK, Cornell T, Quasney MW. Genetic and epigenetic factors in the regulation of the immune response. Curr Opin Pediatr. 2016;28:281-6.

45. Wang H, Jiang D, Li W, Wang S. Increased expression of BPI fold-containing family a member 1 is associated with metastasis and poor prognosis in human colorectal carcinoma. Oncol Lett. 2017;14:4231-6.

46. Dunn LL, de Valence S, Tille JC, Hammel P, Walpoth BH, Stocker R, Imhof BA, Miljkovic-Licina M. Biodegradable and plasma-treated electrospun scaffolds coated with recombinant Olfactomedin-like 3 for accelerating wound healing and tissue regeneration. Wound Repair Regen. 2016;24:1030-5.

47. Mengwasser J, Liu FT, Sleeman JP. Galectin-3 is strongly up-regulated in nonapoptosing mammary epithelial cells during rat mammary gland involution. Glycobiology. 2002;12:129-34.

48. Feinberg TY, Rowe RG, Saunders TL, Weiss SJ. Functional roles of MMP14 and MMP15 in early postnatal mammary gland development. Development. 2016;143:3956-68

49. Liu R, Jin J. Calponin isoforms CNN1, CNN2 and CNN3: regulators for actin cytoskeleton functions in smooth muscle and non-muscle cells. Gene. 2016; 585:143-53.

50. Yako Y, Hayashi T, Takeuchi Y, Ishibashi K, Kasai N, Sato N, Kuromiya K, Ishikawa S, Fujita Y. ADAM-like Decysin-1 (ADAMDEC1) is a positive regulator of epithelial defense against Cancer (EDAC) that promotes apical extrusion of RasV12-transformed cells. Sci Rep. 2018:8:9639.

51. O'Shea NR, Chew TS, Dunne J, Marnane R, Nedjat-Shokouhi B, Smith PJ, Bloom SL, Smith AM, Segal AW. Critical role of the Disintegrin Metalloprotease ADAM-like Decysin-1 [ADAMDEC1] for intestinal immunity and inflammation. J Crohns Colitis. 2016;10:1417-27.

52. Hilborn E, Stål O, Jansson A. Estrogen and androgen-converting enzymes 17ß-hydroxysteroid dehydrogenase and their involvement in cancer: with a special focus on 17ß-hydroxysteroid dehydrogenase type 1,2, and breast cancer. Oncotarget. 2017;8:30552-62.

53. McCoard SA, Hayashi AA, Sciascia Q, Rounce J, Sinclair B, McNabb WC, Roy NC. Mammary transcriptome analysis of lactating dairy cows following administration of bovine growth hormone. Animal. 2016;10:2008-17.

54. Pan $L$, Li Y, Jin L, Li J, Xu A. TRPM2-AS promotes cancer cell proliferation through control of TAF15. Int J Biochem Cell Biol. 2020;120:105683.

55. Darlison MG, Pahal I, Thode C. Consequences of the evolution of the GABA(a) receptor gene family. Cell Mol Neurobiol. 2005;25:607-24.

56. Moua P, Checketts M, Xu LG, Shu HB, Reyland ME, Cusick JK. RELT family members activate p38 and induce apoptosis by a mechanism distinct from TNFR1. Biochem Biophys Res Commun. 2017;491:25-32.

57. Piantoni P, Wang P, Drackley JK, Hurley WL, Loor JJ. Expression of metabolic tissue remodeling, oxidative stress, and inflammatory pathways in mammary tissue during involution in lactating dairy cows. Bioinform Biol Insights. 2010;4:85-97.

58. Kapila N, Sharma A, Kishore A, Sodhi M, Tripathi PK, Mohanty AK, Mukesh M. Impact of heat stress on cellular and transcriptional adaptation of mammary epithelial cells in riverine Buffalo (Bubalus Bubalis). PLoS One. 2016;11: e0157237.

59. Ahmad MK, Abdollah NA, Shafie NH, Yusof NM, Razak SRA. Dual-specificity phosphatase 6 (DUSP6): a review of its molecular characteristics and clinical relevance in cancer. Cancer Biol Med. 2018;15:14-28.

60. Wei F, Hao P, Zhang X, Hu H, Jiang D, Yin A, Wen L, Zheng L, He JZ, Mei W, et al. Etoposide-induced DNA damage affects multiple cellular pathways in addition to DNA damage response. Oncotarget. 2018;9:24122-39.

61. Choudhary RK, Choudhary S, Mukhopadhyay CS, Pathak D, Verma R. Deciphering the transcriptome of prepubertal buffalo mammary glands using RNA sequencing. Funct Integr Genomics. 2019;19:349-62. 
62. Bertram C, Hass R. Matrix metalloproteinase-7 and the $20 \mathrm{~S}$ proteasome contribute to cellular senescence. Sci Signal. 2008;25:pt1.

63. Osman AK, Shintani M. Autophagy in normal tissues of camel (Camelus dromedarius) with focus on immunoexpression of LC3 and LC3B. Biotech Histochem. 2018;4:1-8.

64. Wohlgemuth SE, Ramirez-Lee Y, Tao S, Monteiro APA, Ahmed BM, Dahl GE. Short communication: effect of heat stress on markers of autophagy in the mammary gland during the dry period. J Dairy Sci. 2016;99:4875-80.

65. Gross JJ, Schwarz FJ, Eder K, van Dorland HA, Bruckmaier RM. Liver fat content and lipid metabolism in dairy cows during early lactation and during a mid-lactation feed restriction. J Dairy Sci. 2013;96:5008-17.

66. Bernard L, Bonnet M, Leroux C, Shingfield KJ, Chilliard Y. Effect of sunflowerseed oil or linseed oil on milk fatty acid secretion and lipogenic gene expression in goats fed hay-based diets. J Dairy Res. 2009;76:241-8.

67. Bernard L, Leroux C, Rouel J, Bonnet M, Chilliard Y. Effect of the level and type of starchy concentrate on tissue lipid metabolism, gene expression and milk fatty acid secretion in Alpine goats receiving a diet rich in sunflower-seed oil. Br J Nutr. 2012;107:1147-59.

68. Waldemarson $\mathrm{KH}$, Karlsson BW. Dehydrogenases, nucleic acids and soluble proteins in mammary gland of the Mongolian gerbil during pregnancy, lactation and involution. Comp Biochem Physiol B. 1976;55:109-15.

69. Denis CJ, Deiteren K, Hendriks D, Proost P, Lambeir AM. Carboxypeptidase $M$ in apoptosis, adipogenesis and cancer. Clin Chim Acta. 2013:415:306-16.

70. Compton CW, Cursons RT, Barnett CM, McDougall S. Expression of innate resistance factors in mammary secretion from periparturient dairy heifers and their association with subsequent infection status. Vet Immunol Immunopathol. 2009;127:357-64.

71. Baik MG, Lee MJ, Choi YJ. Gene expression during involution of mammary gland (review). Int J Mol Med. 1998;2:39-44.

72. Malinowski E, Smulski S, Markiewicz H, Kaczmarowski M. The effect of some drugs injection to pregnant heifers on blood antioxidant status. Pol J Vet Sci. 2004;7:91-5.

73. Li H, Sun Y, Zheng H, Li L, Yu Q, Yao X. Parathyroid hormone-related protein overexpression protects goat mammary gland epithelial cells from calciumsensing receptor activation-induced apoptosis. Mol Biol Rep. 2015;42:233-43.

74. Moon SY, Eun HJ, Baek SK, Jin SJ, Kim TS, Kim SW, Seong HH, Choi IC, Lee $\mathrm{JH}$. Activation-induced Cytidine Deaminase induces DNA Demethylation of Pluripotency genes in bovine differentiated cells. Cell Reprogram. 2016;18: 298-308.

75. Muñoz DP, Lee EL, Takayama S, Coppé JP, Heo SJ, Boffelli D, Di Noia JM, Martin DI. Activation-induced cytidine deaminase (AID) is necessary for the epithelial-mesenchymal transition in mammary epithelial cells. Proc Natl Acad Sci U S A. 2013;110:E2977-86

76. Martin E, Palmic N, Sanquer S, Lenoir C, Hauck F, Mongellaz C, Fabrega S, Nitschké P, Esposti MD, Schwartzentruber J, et al. CTP synthase 1 deficiency in humans reveals its central role in lymphocyte proliferation. Nature. 2014; 510:288-92.

77. Bautista CJ, Montaño S, Ramirez V, Morales A, Nathanielsz PW, Bobadilla NA, Zambrano E. Changes in milk composition in obese rats consuming a highfat diet. Br J Nutr. 2016;115:538-46.

78. Shimizu Y, Miyakura R, Otsuka Y. Nuclear receptor subfamily 4, group a, member 1 inhibits extrinsic apoptosis and reduces caspase-8 activity in H2O2-induced human HUC-F2 fibroblasts. Redox Rep. 2015;20:81-8.

79. Aslebagh R, Channaveerappa D, Arcaro KF, Darie CC. Comparative twodimensional polyacrylamide gel electrophoresis (2D-PAGE) of human milk to identify dysregulated proteins in breast cancer. Electrophoresis. in press. https://doi.org/10.1002/elps.201800025.

80. Wan W, Liu Q, Lionakis MS, Marino AP, Anderson SA, Swamydas M, Murphy PM. Atypical chemokine receptor 1 deficiency reduces atherogenesis in ApoE-knockout mice. Cardiovasc Res. 2015;106:478-87.

81. Chen X, Cheng Z, Werling D, Pollott GE, Salavati M, Johnson KF, Khan FA, Wathes DC, Zhang S. Bovine P-selectin mediates leukocyte adhesion and is highly polymorphic in dairy breeds. Res Vet Sci. 2016;108:85-92.

82. Zhang H, Jiang H, Fan Y, Chen Z, Li M, Mao Y, Karrow NA, Loor JJ, Moore S, Yang Z. Transcriptomics and iTRAQ-proteomics analyses of bovine mammary tissue with Streptococcus agalactiae-induced mastitis. J Agric Food Chem. 2018;66:11188-96.

83. Andersen $\mathrm{CL}$, Jensen JL, Ørntoft TF. Normalization of real-time quantitative reverse transcription-PCR data: a model-based variance estimation approach to identify genes suited for normalization, applied to bladder and colon cancer data sets. Cancer Res. 2004;64:5245-50.
84. Vandesompele J, De Preter K, Pattyn F, Poppe B, Van Roy N, De Paepe A, Speleman F. Accurate normalization of real-time quantitative RT-PCR data by geometric averaging of multiple internal control genes. Genome Biol. 2002;3:RESEARCH0034.

85. Ruijter JM, Ramakers C, Hoogaars WM, Karlen Y, Bakker O, van den Hoff MJ, Moorman AF. Amplification efficiency: linking baseline and bias in the analysis of quantitative PCR data. Nucleic Acids Res. 2009;37:e45.

86. Pfaffl MW. A new mathematical model for relative quantification in real-time RT-PCR. Nucleic Acids Res. 2001;29:45e.

87. Najafpanah MJ, Sadeghi M, Bakhtiarizadeh MR. Reference genes selection for quantitative real-time PCR using RankAggreg method in different tissues of Capra hircus. PLoS One. 2013;8:e83041.

88. Zhang GW, Lai SJ, Yoshimura Y, Isobe N. Expression of cathelicidins mRNA in the goat mammary gland and effect of the intramammary infusion of lipopolysaccharide on milk cathelicidin-2 concentration. Vet Microbiol. 2014; 170:125-34.

\section{Publisher's Note}

Springer Nature remains neutral with regard to jurisdictional claims in published maps and institutional affiliations.
Ready to submit your research? Choose BMC and benefit from:

- fast, convenient online submission

- thorough peer review by experienced researchers in your field

- rapid publication on acceptance

- support for research data, including large and complex data types

- gold Open Access which fosters wider collaboration and increased citations

- maximum visibility for your research: over $100 \mathrm{M}$ website views per year

At BMC, research is always in progress.

Learn more biomedcentral.com/submissions 